\title{
La alquería de Pereila, un poblamiento andalusí en la Algarbía malagueña ${ }^{1}$
}

\author{
The Farmstead of Pereila, an Al-Andalusian Settlement in \\ the Algarbía District (Málaga)
}

\author{
Antonio ORDÓÑEZ FRÍAS \\ Universidad de Cádiz \\ aofrias60@hotmail.com \\ Agustina Aguilar Simón \\ Archivo Municipal de Málaga \\ aaguilar@malaga.eu
}

Recibido: $24 / 02 / 2015$

Aceptado: 27/05/2015

\section{RESUMEN}

El poblamiento rural de origen andalusí en la antigua Algarbía malagueña es un gran desconocido para la historiografía medieval. Las excavaciones y prospecciones con metodología arqueológica son prácticamente inexistentes y el recurso a la documentación escrita, en concreto la de origen castellana, ha dado un resultado muy limitado. Como excepción tenemos la información correspondiente al antiguo espacio residencial de Pereila y su territorio. La alquería estaba situada dentro del actual término municipal de Coín (Málaga) y un pleito en el 1537 entre el cabildo Catedralicio de Málaga y los beneficiados de Coín por el cobro del diezmo de dicho lugar, nos ha aportado una información valiosa sobre los límites territoriales del poblamiento, y en menor medida, de sus espacios de trabajo. También utilizaremos la metodología propia de la arqueología extensiva y los principios de la arqueología hidráulica que nos servirán para complementar la información aportada por la documentación escrita.

Palabras clave: Algarbía, Pereila, Alquería, Coín, pleito en el 1537, diezmo, arqueología extensiva, arqueología hidráulica.

\begin{abstract}
Very little is known in medieval historiography concerning rural settlements in the Algarbía district (Málaga) under Muslim rule. Scarcely any archaeological excavations or surveys have been conducted and recourse to written documents, specifically those of Castilian origin, has yielded very limited results. One exception to this rule is the information pertaining to the Pereila farmstead and its lands, located in what is the present day municipality of Coín (Málaga). A lawsuit in 1537 between the Málaga cathedral chapter and the beneficiaries of Coín concerning collection of the tithe from this site has provided valuable information about the territorial boundaries of the settlement, and to a lesser extent about its
\end{abstract}

${ }^{1}$ Este trabajo forma parte de una Actividad Arqueológica Puntual con recogida de materiales autorizada por la Delegación de Cultura de la Junta de Andalucía en Málaga cuyos objetivos es el estudio del poblamiento y de los espacios de trabajo andalusíes en la subcuenca de río Grande-Málaga- (nº Expte. AA 39/14). 
workspaces. The methodology of extensive archaeology and the principles of hydraulic archaeology have also been employed to complement the information provided by the written documentation.

Key Words: Algarbía, Pereila, Farmstead (Al-Qarya), Coín, 1537 Lawsuit, Tithe, Extensive Archaeology, Hydraulic Archaeology.

Sumario: 1. Pereila dentro de la documentación escrita castellana; el pleito de 1537. 2. El marco geográfico: límites y superficie territorial. 3. Los diferentes usos del territorio: áreas de trabajo y espacio residencial. 3.1. Los diversos sistemas de irrigación de Pereila Alta. 3.2. El espacio residencial. 3.3. Valdeperales y sus espacios de trabajo. 3.4. El territorio común. 4. Su evolución, desde alquería andalusí a poblamiento mudéjar-morisco. 5. Conclusiones. 6. Bibliografía.

El antiguo territorio de la alquería de Pereila está incluido en el actual término municipal de Coín, provincia de Málaga, dentro de la comunidad Andaluza y correspondería con los actuales partidos rurales de Valdeperales y Pereila Alta. Un pleito de términos del 1537 conservado en el Archivo Catedralicio de Málaga se ha mostrado como una fuente de información muy precisa sobre este territorio en las últimas décadas del período nazarí, donde se especifican una zonificación económica en que se hace una división entre espacios comunes de varias alquerías, zonas de cultivos de irrigación y terrenos de cultivos de secano. En su economía tenía gran importancia la agricultura de irrigación cuyo suministro hídrico lo proporcionaba la fuente de la Reyna y las acequias de Valdeperales y del Olivar, estas últimas tenían sus puntos de captación en el río Nacimiento. Igualmente se recoge una detallada información sobre sus límites administrativos. Dicha alquería, al menos desde finales del periodo nazarí, formaba una entidad autónoma con un territorio propio, limítrofe con las alquerías de la Villeta al suroeste, que ocuparía buena parte del actual término de Monda, al norte con Dakwan, la actual Coin, que para la fecha ya estaría en un proceso avanzado de urbanización que le acercaría al estadio de medina, y al este con las alquerías de Benamaquí y Xubrique. Tras la conquista castellana del territorio, en 1485, fue incluida dentro del término de la villa de Coín².

Con este estudio pretendemos realizar una aproximación a la estructura poblacional y territorial de Pereila en las últimas décadas del siglo XV, utilizando básicamente las fuentes documentales castellanas y, en menor medida, el escaso registro arqueológico existente. También se analizará su evolución durante la primera mitad del siglo XVI en que, tras la conquista castellana, se produce un reajuste poblacional y territorial, con algunas estructuras de origen andalusí que perviven, fundamentalmente en aquellas comunidades en que existía una mayoría de población morisca, y que se van modificando bajo la presión aculturadora y represiva de la sociedad dominante 3 .

2 "Los castellanos intentaron adaptar las tierras ocupadas a sus necesidades provocando cambios sustanciales en su organización y aprovechamiento. Así modifican los términos de las antiguas alquerías al adscribirlas a otros lugares, casi siempre mayores..." TRILlo SAN José, "El paisaje vegetal en la Granada islámica" 1999 , p. 144. Este sería el caso de Coín, la antigua Dakwan nazarí, que absorbe los territorios de una serie de alquerías circundantes, entre ellas Pereila.

3 Una serie de Pragmáticas emitidas por la Corona (1502, 1516, 1518, 1526 y 1566) van subyugando paulatinamente la cultura morisca. Estas transformaciones también tienen su reflejo en el registro arqueológico 


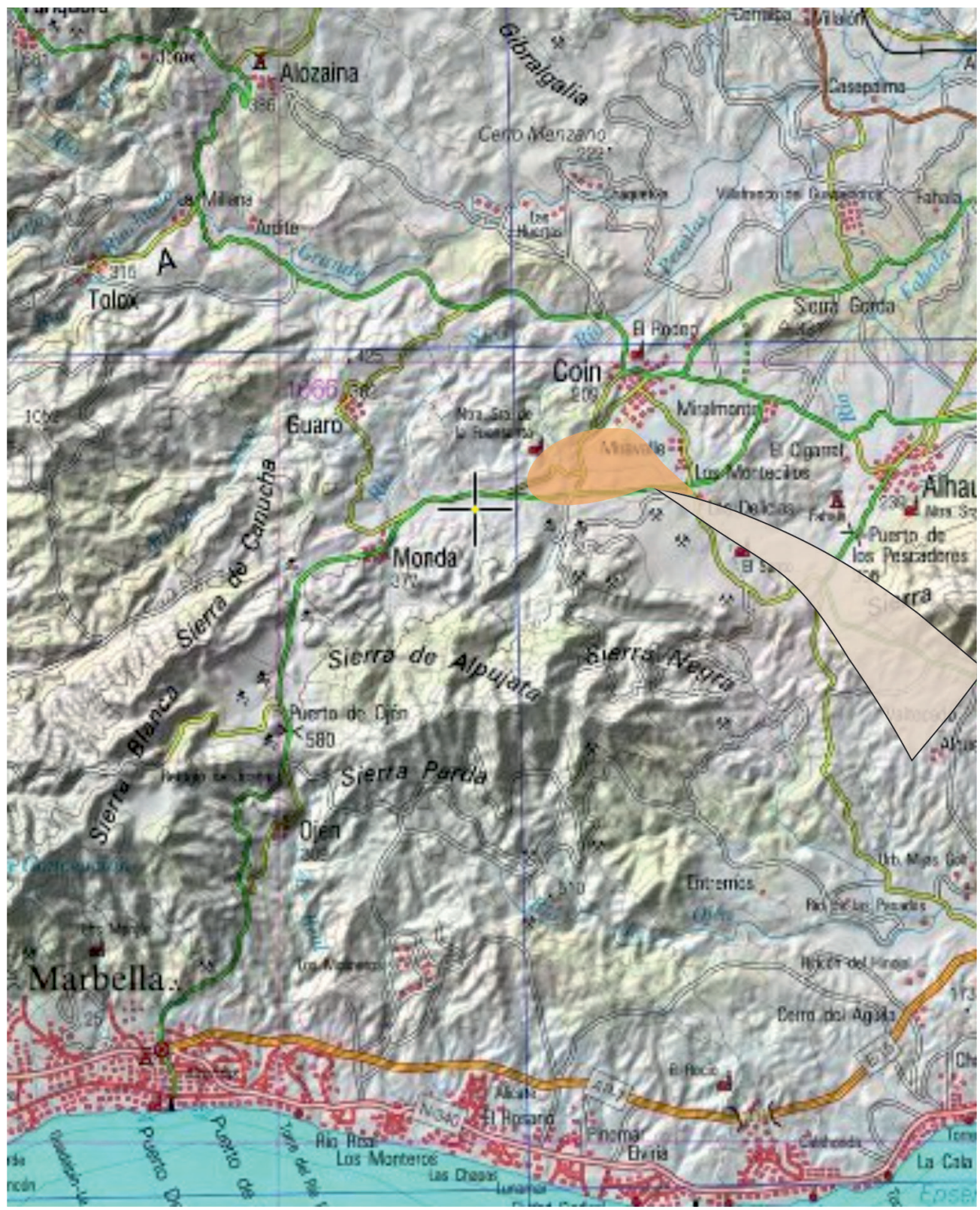

Fig. 1. Localización de Pereila Alta dentro de la actual provincia de Málaga.

de determinados espacios residenciales que estuvieron habitados exclusivamente por moriscos. Tal es el caso de la alquería de la Villeta (Monda-Málaga-) en que en un trabajo sobre material cerámico (Ordóñez Frías, "La cerámica medieval y moderna", pp. 207-240) fruto de una excavación realizada en 1990 (Acién Almansa y Rambla Torralbo, "La evolución de un hisn musulmán”, pp. 273-294) ha dado como resultado la existencia de determinadas tipologías de origen cristiano que aparentemente son reflejo de una aculturación en el plano material. 
Los estudios sobre las transformaciones en el ámbito rural en los últimos años del periodo nazarí y tras la conquista cristiana gozan de una importante tradición. La abundancia de documentación castellana ha facilitado la realización de estudios, tanto locales como regionales, contando con una amplia nómina de investigadores de los cuales no pretendemos realizar una revisión exhaustiva y solo destacaremos aquellos trabajos que consideramos más significativos. Abarcando el occidente del antiguo obispado de Málaga esta la obra de López de Coca Castañer: "La tierra de Málaga a fines del siglo XV"4 con un estudio tanto económico como social y territorial, basado en los Libros de Repartimientos, y en menor medida en reales cédulas y documentación diversa de finales del siglo XV. Acién Almansa también realizó una investigación similar aunque centrada en el ámbito de la Serranía de Ronda ${ }^{5}$. Bejarano Robles y Bejarano Pérez han efectuado sendos trabajos sobre finales del siglo XV tomando como documentación básica los Repartimientos de Málaga que incluían la capital y los principales núcleos poblacionales de la antigua Algarbía malagueña ${ }^{6}$. Otro investigador destacable, dentro del ámbito malagueño, es Cabrillana Ciezar cuyos trabajos se fundamentan en los protocolos notariales de la primera mitad del siglo XVI, y en menor medida, en los Repartimientos de finales del siglo $\mathrm{XV}^{7}$. Relacionado con la temática de la fiscalidad y la cuestión morisca, Galán Sánchez utiliza una variada gama de documentación archivística centrándose en la primera mitad del siglo $\mathrm{XVI}^{8}$. Malpica Cuello utiliza con asiduidad los recursos documentales tanto a nivel epistemológico como en estudios concretos. Tales son los casos de la alquería de Turillas ${ }^{9}$ o del territorio de Loja ${ }^{10}$. Trillo San José emplea también las fuentes castellanas de finales del XV y principio del XVI, además de documentación de origen nazarí, para una temática recurrente de la alquería y su territorio ${ }^{11}$. Tomando como base los bienes hábices de algunas mezquitas, en 1502, y en menor medida los Libros de Apeos y Repartimientos, Espinar Moreno analiza el poblamiento y su estructura en el Valle de Lecrín (Granada) ${ }^{12}$. Peinado Santaella en sus investigaciones sobre dos alquerías de la Vega granadina, Chauchina y el Jau, también se vale de documentación castellana, algunos de ellos romanceadas y con una temática vinculada con el poblamiento, el paisaje agrario y la propiedad ${ }^{13}$. Dentro de la Algarbía malagueña, comarca objeto de nuestro estudio, destaca la figura de Martínez Enamorado con una serie de obras, algunas que abarcan todo el ámbito provincial ${ }^{14}$ y otras centradas en Dakwan y su entorno $^{15}$, en que utiliza tanto fuentes documentales como arqueológicas. Digno de

${ }^{4}$ LÓPEZ DE COCa CASTAÑer, La tierra de Málaga a fines del siglo XV.

5 Acién Almansa, Ronda y su Serranía.

${ }^{6}$ Bejarano Robles, Los Repartimientos de Málaga, I, II, III y V. Bejarano Pérez, Los Repartimientos de Málaga IV.

${ }^{7}$ Cabrillana Ciezar, El problema de la tierra en Málaga.

${ }^{8}$ Galán Sánchez, "Poder y fiscalidad en el reino de Granada", pp. 67-98.

${ }^{9}$ Malpica Cuello, Turillas, alquería del Alfoz.

${ }^{10}$ Malpica Cuello, "El territorio de Loja", pp. 233-254.

${ }^{11}$ Trillo SAn José, "La alquería y su territorio en Al-Andalus", pp. 243-262.

${ }^{12}$ Espinar Moreno, "La población de Durcal del Valle", pp. 57-82.

13 Peinado Santaella, "Una aportación documental sobre el poblamiento”, pp. 19-92.

${ }^{14}$ Martínez Enamorado, Al-Andalus desde la periferia.

${ }^{15}$ Martínez Enamorado, "La Algarbía como realidad geohistórica", pp. 57-95. 
destacar por el minucioso trabajo realizado, es el estudio que efectuó sobre Torrox, localidad situada en la Axarquía malagueña, en que realiza una reconstrucción retrospectiva de los últimos años de la sociedad nazarí ${ }^{16}$. También de este autor y de Gómez Armada es el reciente trabajo sobre Casarabonela basado en su Libro de Repartimiento de $1572^{17}$. López García y Ordóñez Frías son dos investigadores que también han centrado sus estudios sobre la Algarbía. El primero ha realizado un trabajo sobre la hidráulica de origen andalusí en Tolox ${ }^{18}$ en que utiliza el Apeo y Repartimiento de 1572. El segundo trata la temática de espacios irrigados y población en los pagos de Jorox (Alozaina) ${ }^{19}$ y Alpujata (Monda) ${ }^{20}$.

Vemos como esta tendencia de estudiar la sociedad de finales del siglo XV, y la mudéjar-morisca, tiene en la actualidad un peso específico relativamente elevado, probablemente como consecuencia de la escasez de textos andalusíes que aporten una información relevante, la abundancia de documentación jurídica castellana y ante la ineficacia de una arqueología medieval en que prima más los aspectos de gestión que la investigación en sí misma.

\section{PEREILA DENTRO DE LA DOCUMENTACIÓN ESCRITA CASTELLANA; EL PLEITO DE 1537}

En junio del 1537 se produce un pleito ${ }^{21}$ entre el cabildo de la Catedral de Málaga y los beneficiados de la villa de Coin sobre los derechos de cobro de los diezmos del lugar o alquería de Pereila ${ }^{22}$. Los primeros afirmaban que dicho impuesto pertenecía al Cabildo alegando que el lugar de Pereila nunca había formado parte del término de Coin "...que siendo como fue el lugar de Pereyla de moros situado en término de la dicha villa (Coin) y tener juridicion y fabrica le pertenece la cuarta parte de su diezmo..."23, es decir mantenían el postulado de que cuando en 1485 Dakwan fue conquistada por los castellanos, Pereila ya existía como núcleo autónomo. Los beneficiados, en contraposición, intentan demostrar que dicho lugar siempre estuvo integrado dentro del término municipal de Coin: "Yten si saben que Pereyla no tiene termino distinto ni apartado porque todo ello y la tierra que ay fasta amojonar con Monda es termino dado y declarado por los repartidores de términos y reforma del ba-

\footnotetext{
16 Martínez Enamorado, Torrox. Un sistema de alquerías.

17 Gómez Armada y Martínez Enamorado, Repartimiento de los bienes de los moriscos de Casarabonela.

18 López GArcía, “El regadío de origen andalusí en la Sierra de las Nieves”, pp. 187-216.

19 OrdóÑEz FríAs, "Hidráulica y poblamiento andalusí en el valle de Jorox”.

20 ORDóÑEz FríAs, "Los sistemas de irrigación de origen andalusí".

${ }^{21}$ Archivo Catedralicio de Málaga (en adelante ACM), Leg. 4, n 35, s/f, 1537 (en adelante Pleito).

22 Existe un breve trabajo sobre la alquería de Pereila que está basado también en este pleito. Fue publicado por Cabrillana Ciézar en 1993. Desde nuestro punto de vista tiene algunas imprecisiones siendo la más destacada aquella que sitúa el espacio residencial en el Llano de la Virgen distante casi un kilómetro del lugar en que consideramos que estuvo dicho espacio residencial; (CABRILlanA, El problema de la tierra en Málaga, pp.120-123).

23 ACM, Pleito.
} 
chiller Serrano por mandato de los Reyes Católicos..."24. Pero, como hemos mencionado, uno de los aspectos más interesante de dicho Pleito es cuando los testigos presentados por el cabildo Catedralicio responden a la cuestión que se plantea sobre los límites de la alquería proporcionándonos una serie de hitos geográficos que han sido fáciles de rastrear y de ubicar coincidiendo, en su mayoría, con topónimos existentes en la actualidad y todos ellos castellanizados ${ }^{25}$, probablemente desde principios del siglo XVI. Ello es así porque la información que proporcionan las fuentes documentales no son prolijas en detalles relacionados con el territorio que ocupaban las alquerías bajomedievales.

El Pleito se estructura en dos partes. La primera está ocupada por la comparecencia de los testigos presentados por el Cabildo que a su vez se divide en dos partes. En la primera parte o "Preguntas Generales" se entrevista a doce testigos, todos ellos cristianos viejos y vecinos de Coín salvo uno, Juan Aldovon, morisco vecino de Casapalma, pero cuyos padres residieron en Pereila a finales del siglo XV. Se les formulan una serie de preguntas siendo las más significativas aquellas que estaban relacionadas con el cobro del diezmo (beneficiados o Cabildo), cultivos y cultivadores en Valdeperales, límites del territorio de Pereila, entre otras. Es curioso como a la pregunta sobre los límites de la alquería ninguno de los testigos tiene conocimiento de ellos a pesar de que incluso se busca en Casapalma a Juan Aldovon que habitó en la zona hasta las primeras décadas del siglo XVI. En la segunda o "Probança del Cabildo" se realizan preguntas similares a veintinueve testigos, veinte moriscos y nueve cristianos viejos. En este caso la mayoría de los testigos moriscos contestaron a la pregunta sobre los límites de territorio lo que nos aporta una información valiosa.

\section{EL MARCO GEOGRÁFICO: LÍMITES Y SUPERFICIE TERRITORIAL}

La información sobre el territorio que ocupaba la alquería de Pereila es proporcionada, fundamentalmente, por los testigos que presenta el Cabildo. Llama poderosamente la atención que de los veintinueve testigos que contestaron a las preguntas relacionadas con las "Probanças del Cabildo", veinte son moriscos ${ }^{26}$ que residen en la villa y lugar de Monda y Guaro ${ }^{27}$ respectivamente, y solo nueve son cristianos viejos, ocho vecinos

${ }^{24}$ Ibidem. Como veremos más adelante este intento por parte de los beneficiados de incluir la alquería de Pereila dentro del Coín islámico, entrará en clara contradicción con una serie de documentos castellanos de finales del siglo XV y la primera mitad del XVI que evidencian que dicho lugar, en época andalusí, tenía su propio término y autonomía para la gestión de este.

25 Sólo uno de los testigos moriscos, Diego de ysbilis, cuando especifica los límites territoriales de Pereila hace referencia a un cerro con toponimia arábiga: “...Pereyla se apartaba del termino de Coyn desde la cruz donde estava a dar por el peñón que llamaban adbi dubt...” ACM, Pleito.

${ }^{26}$ Pedro Arraquez, Juana Ruzu, Ruiz Albayte, Juan de Villalva el Raqui, Lorezo Haquen, Zacarias Alfox, Lorezo Alfox, Francisco Camota alguacil, Diego Rantro Azus, Diego Almacaz, Martín Aroba Queyle, Sebastian Azemite, Luis Albadir herrero, Juan Arruro, Cristobal el Rami, Juan Almocar, Lorenzo Almocar, Lorenzo Jurgel, Amyn Zuleyman alcalde de Guaro y Andres Algarí. ACM, Pleito.

${ }^{27}$ A diferencia de Coín/Dakwan, Guaro y Monda se rindieron sin resistencia armada en 1485 tras la caída de Ronda. Sus respectivas cartas de seguro son recogidas en el caso de Monda por Perez De Pulgar, Crónica de los señores Reyes Católicos, capítulo XLII. 
de Coin, y uno de Monda ${ }^{28}$. Esta mayoría de testigos moriscos no es casual y se basa en el conocimiento que poseían del territorio al final del emirato nazarí. El Cabildo sabe que esta argumentación puede ser fundamental para demostrar sus derechos al cobro del diezmo y para ello recurre a algunos de los antiguos pobladores de la alquería de Pereila. Así ocurre con Lorenzo Jurgel vecino de Guaro en 1537 en que “...este testigo morava con sus padres (Pereila) y después que se caso en Coyn siendo este reyno de Granada de moros..." ${ }^{29}$ o con Cristobal el Ramí vecino de Guaro para las misma fecha "...que este testigo tiene memoria del dicho lugar de Pereyla desde que hera nyño porque en tienpo de moros moravan su padre y madre en Pereyla..." ${ }^{30}$. Igual ocurre con Ruyz Albayte "... porque su padre sabia muy bien las tierras que abia morado en Benamaquyz junto a Coyn en tienpo de moros..."31.

Vamos a analizar los diferentes topónimos que los testigos del Cabildo ${ }^{32}$ exponen en las comparecencias con el propósito de delimitar el territorio de la antigua alquería de forma lo más precisa posible y así poder establecer su superficie total. No todos ellos coinciden en los mismos puntos de identificación territorial, aunque si hay una mayoría que repiten hitos similares.

El pago de Viñas Viejas consta en el Pleito como el límite oeste de los territorios de Pereila: “...y a dar a las víñas viejas de Coyn...”. Durante el siglo XVI son frecuentes las alusiones a este pago ${ }^{33}$, siendo interesante, por las referencias que nos aportan sobre la ubicación de dicho lugar, dos protocolos notariales de 1566: “...y otro olibar en el pago de biñas viejas en el camino de Monda...”34, “...en el pago de biñas viejas que alinda con Fernando Ortega y con heredad de Albarracin y con el ryo Pereyla..." "35. La última mención relacionada con este topónimo la encontramos en el siglo XVIII: "Otro olibar el que compone de una obrada la que esta en el partido de Viñas Viejas..." ${ }^{36}$. Ya en el siglo XX dicho nombre ha desaparecido del mapa rural de Coín, aunque se conserva como microtoponimia entre algunos agricultores de la zona. A tenor de las descripciones anteriores lo situamos en una franja de terreno que iría desde la margen izquierda del camino real de Coin a Monda, sentido Monda, hasta los límites del cauce de río Pereila. En la actualidad consta en escrituras de propietarios como Pereila Alta.

Con el nombre de la "cruz" se identifica en el Pleito un cruce de caminos en el que existía y existe una cruz: “...desde donde estaba una cruz que estaba en el camino que iba

${ }^{28}$ Sólo Alonso de Atienza vive en Pereila, pero segregado de la población morisca al residir en el molino hidráulico que estaba junto al camino de Coín a Monda (de la Pasada), cuyo propietario era Rodrigo de Alcázar y que tiene sus orígenes en el período bajomedieval; Bejarano Pérez, Los Repartimientos de Málaga IV, 2004, p. 321.

${ }^{29}$ ACM, Pleito

${ }^{30}$ Ibidem.

${ }^{31}$ Ibidem.

${ }^{32}$ Los testigos presentados por los beneficiados declararon que Pereila no tenía términos propios y por lo tanto no enumeraron unos límites individualizados. Sin embargo tampoco se realizó ningún tipo de descripción de términos.

${ }^{33}$ AHPM, P-6598, s/f, 1551, AHPM, P-6553, s/f, 1560, AHPM, P-6549, s/f, 1562...

${ }^{34}$ AHPM, P-6555, s/f, 1566.

${ }^{35}$ Ibidem.

${ }^{36}$ Bermúdez Mendez y Martín Chicano, Coin en 1572, p. 260. 
de Monda a Coyn..." "37, “...una cruz que esta debajo de la questa que va de Monda a Coyn donde se juntan el camino de Monda con el camino de la Fuensanta..." ${ }^{38}$. Es citada por catorce testigos. Hay que destacar la referencia recogida sobre dicha cruz en el Catastro de Ensenada en el que se hace una descripción muy parecida a la realizada en el Pleito: "Otro olivar en dicho partido de la Cruz de Monda [...] Y por medio de este olivar pasan dos caminos, el uno va a la ermita de Nuestra Señora de la Fuensanta y otro que de esta villa va a la de Monda..." 39 . Es la que actualmente se denomina la "Cruz de Piedra" situada en una bifurcación entre dos caminos, el de la izquierda que se denomina camino Viejo de Monda que iba a dicha villa y a Pereila, vía de probable origen andalusí; y el de la derecha que conduce a la ermita de la Fuensanta.

La villa o cerro de Alcaraz, son dos hitos que identificamos como un mismo lugar: "...de ally atraviesa un arroyo de agua dejando el cerro de Alcaraz en lo de Pereyla..." "...e dar a un cerro que llaman la villa de Alcaraz y de ally desciende al vado del río de Alcaraz..." ${ }^{\prime 1}$. Se repite en las declaraciones de ocho testigos. Estos hitos no vuelven a aparecer en la documentación escrita posterior a 1537, ni tampoco lo hacen en la toponimia local. Sin embargo dado el grado de precisión con que vienen descritos en el Pleito son fáciles de identificar coincidiendo, en la actualidad, con un cerro situado junto a la entrada al pago de Valdeperales cuando se accede desde el antiguo camino de Coín a Monda y en la vertiente que ocupa el partido rural del Arrumbadero. Aún se conserva en la cúspide de dicho cerro restos de lo que fue una construcción de gran tamaño compuesta por múltiples estancias y que probablemente estuviera en uso hasta época contemporánea.

"El cerro de las Lombardas" es otro de los topónimos referidos en el Pleito: “...y de ally a dar derecho al cerro que dicen de las Lombardas...."42, "...y de ally camino ariba a dar al cerro que llaman de las Lombardas..." ${ }^{43}$. Fue mencionado por nueve testigos. Ya aparece a finales del siglo XV cuando en el Repartimiento de Coín se dice: "Otro trance que comiença junto con este que lo parte el agua de los molinos y por la parte de abaxo va junto con las huertas y por la otra va por las piedras de las lonbardas a partyr con lo de Barrionuevo..." ${ }^{\prime 4}$. En la actualizad se denomina cerro Carranque aunque en las consultas realizadas en el Registro de la Propiedad de Coín hemos podido comprobar que permanece como "cerro de las Lombardas" a nivel de escritura de propietarios. Está situado en el término municipal de Coín, entre los partidos rurales de Valdeperales, el Arrumbadero y los Llanos. Se trata de un promontorio apenas a dos kilómetros del casco urbano que cae de forma suave hacia el camino de los Llanos y de forma abrupta hacia Valdeperales.

"El vado del río Alcaraz" o el "vado del río de Coín", creemos que ambos son el mismo lugar. Coincidiría con el antiguo vado del río Nacimiento en su cruce con el camino de los Llanos, hoy día franqueado por un puente: “...y de ally desciende al vado del rio

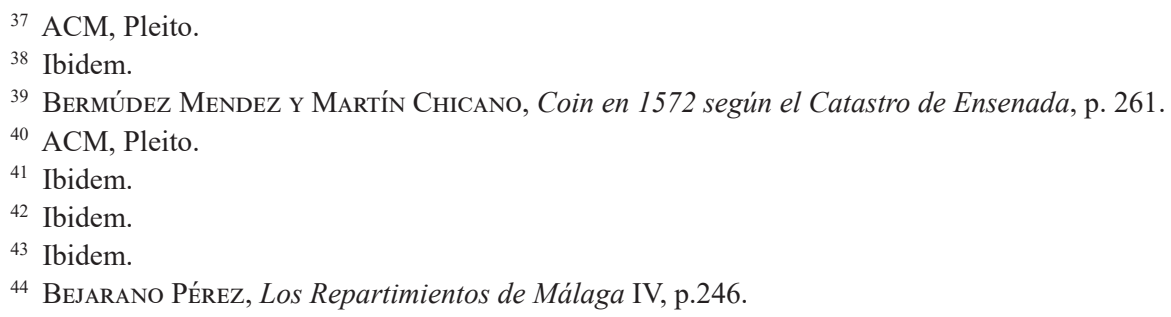


Alcaraz..."45, "a partir de ally va a dar con el vado del ryo de Coyn..." ${ }^{" 46}$. Es mencionado por cuatro testigos y no tenemos constancia de su existencia en otras fuentes documentales ni en la toponimia local.

La surgencia del río Nacimiento marcaba el límite sureste de la alquería de Pereila: “... rio arriba hasta dar en el nacimiento del agua..." Coyn"48. Dicho topónimo es recogido por los testigos en doce ocasiones. Hoy día es un lugar muy conocido en Coín al cual se le denomina "el Nacimiento" con cuyas aguas se riegan, mediante un complejo sistema de acequias, aproximadamente unas $665 \mathrm{Ha}^{49}$. En la actualidad se está desarrollando un trabajo de investigación basado en la metodología de la arqueología hidráulica para delimitar los espacios irrigados de origen andalusí que tienen sus tomas en las agua de este río ${ }^{50}$.

El topónimo de la Fuensanta corresponde con el partido rural del mismo nombre: “... deslindando con las tierra de la Fuensanta con una cuevas y peñas que estaban en el cerro..." "51, “...otro mojón encima de la Fuensanta..." 52 . Tiene su origen en la existencia de una fuente y pequeña gruta en la que, probablemente, se practicara algún tipo de culto desde época ancestral. La ermita, tal como la conocemos actualmente, fue construida en el $1680^{53}$, aunque ya hay indicios de su existencia, al menos, desde $1527^{54}$. La mencionan cuatro de los testigos del Pleito. También es un partido rural bien conocido en la actualidad.

Con el nombre de "los Espartales" aparece en el Pleito una zona que delimita Pereila en parte de su sector sur: "...y hacia los espartales otro mojon..." , “...a dar a las viñas Viejas de Coyn y de ally al Espartal...”. Es poco frecuente su aparición en la documentación del siglo XVI: “...que alinda con guertas de Ana Luysa de Alvarado y el camino y cañada que va a los espartales..." 55 , “...en Coín, en el Partido de Valdeperales linde con Los Espartales..." ${ }^{156}$. En la actualidad dicho lugar ha desaparecido de la microtoponimia local. Sin embargo tenemos indicios suficientes que nos permiten proponer su ubicación en la zona inferior del llano de Matagallar cuando este hace contacto con las tierras del partido rural de los Llanos, abarcando también el pago del Piejo. Esta suposición viene fundada porque tradicionalmente ha sido lugar de extracción de esparto. Así tenemos testimonios orales de cuadrillas que desde los pueblos limítrofes venían a la zona dada la orografía

45 ACM, Pleito.

46 Ibidem.

47 Ibidem.

48 Ibidem.

49 Dato obtenido de las "Ordenanzas de la Comunidad de Regantes Llanos a Juntillas del Nacimiento de Coin (Málaga)” p. 4.

${ }^{50}$ En el Repartimiento de Coin de 1492 se recogen ciento cincuenta fanegas de tierra de regadío, sin contar aquellas relacionadas con las mercedes reales. La mayoría de ellas regadas con las aguas del río Nacimiento. Bejarano Robles, Los Repartimientos de Málaga, I, 1985, p. 365.

51 ACM, Pleito.

52 Ibidem.

53 Boletín Oficial de la Junta de Andalucía, n83, 1987, pp. 4717-4720.

${ }^{54}$ AMM, Escribanía del Cabildo, Vol. 3, Carp. 9, fol.68, 1527. Antonio de la Serna, vecino de Coín, se le concede tierras de monte que lindan con la ermita de la Fuensanta y con sierra Pelada.

55 AHPM, P-6555, s/f, 1564.

${ }^{56}$ AMM, Libro de Composiciones, Vol. 123, fol. 379-379v, 1582. 
suave del terreno y la abundancia de esparto. El sustrato geológico es de predominio de las calizas de tipo dolomías con intromisiones de peridotitas, poseyendo una edafología poco desarrollada que ha dado lugar a suelos muy pobres, poco apto para la agricultura.

Hay, también, algunas referencias que nos describen con bastante precisión los límites de la alquería, especialmente los colindantes con el territorio de Monda:

...desde la cruz va por el camino de Pereyla adelante hasta subir sobre las viñas de Coyn que están en la cara de la sierra y subidos arriba aguas vertientes hacia el camino de Monda en la mano hasta dar en rio y todo esto queda a mano izquierda por Pereyla salvo el molino de Rodriguez de Alcaçar con sus vancales y pasado el rio del molino hacia Monda hasta llegar a tierras de la Fuensanta [...] y yendo deslindando con tierras de la Fuensanta por una peñas y cuevas que estaban en el cerro [...] hasta llegar a los mojones del termino de Monda...57.

Las peñas y cuevas a que se aluden en la Fuensanta son visibles en la cara este del cerro donde existe una serie de cortados con cárcavas que marcaría uno de los límites entre Coín y Pereila, limites que quedarían completados con los "mojones de Monda". Estas demarcaciones han permanecido sin modificaciones desde finales del siglo XV hasta la actualidad.

Las "viñas de Coyn", según esta descripción, la situamos en la margen izquierda del río Pereila, por encima del antiguo poblamiento, y cercanas a la cordada que separaría el río del camino real que va a Monda. Tenemos testimonio de la existencia de estas viñas ya a finales del siglo $\mathrm{XV}$ :

Otro tranço dendel el arroyo del camino de Monda fasta la cunbre arryba de la viñas de Barahona y la cunbre arryba y acaba en la viña el Verde e la de Pedro Velasco e este se ha començar a medir de la parte de hazya el camino de Monda [...] Y quedan de la otra parte del ryo de Pereyra de un cabo e del otro fasta doze aranzadas de viñas que tenia el alcayde de Monda encima de las huertas ${ }^{58}$.

También es importante señalar como aguas abajo del vado que existía junto al molino de Alcaraz, en las inmediaciones del antiguo camino real de Coín a Monda, río Pereila ya no pertenecía a la jurisdicción de la alquería, estando dentro del territorio de Dakwn/ Coin, según hace constar Juan Almodóvar, testigo del Cabildo: "quedando dentro de lo de Pereyla unos vancales que están dentro desta parte del rio bajo el camino Real..." 59 .

Con todos estos hitos hemos realizado un mapa de la antigua alquería que nos proporciona una superficie total de $3702165 \mathrm{~m}^{2}$ y un perímetro de $10 \mathrm{Km}$ (Fig. 2). Vemos como el territorio se divide en tres áreas unidas entre sí; el núcleo de Pereila Alta, Valdeperales y una cuña que se introduce hacia la surgencia del río Nacimiento con la intención de captar sus aguas conduciéndolas hasta Valdeperales.

En definitiva se trata de una aproximación a un conocimiento territorial no solo cuantitativo, sino también cualitativo, con unos referentes geográficos bien definidos en que la posibilidad de un margen de error elevado se minimiza ante la precisión de los datos que

\footnotetext{
${ }^{57}$ ACM, Pleito.

${ }^{58}$ Bejarano Pérez, Los Repartimientos de Málaga IV, p.246.

${ }^{59}$ ACM, Pleito.
} 
nos aportan las fuentes documentales. No es un ente territorial de grandes dimensiones si lo comparamos con la información recogida por Trillo San José sobre la superficie de las alquerías cuando dice: "La distancia que más frecuentemente aparece en los textos es la que un pastor con su ganado recorre en un día de camino volviendo para pernoctar en la alquería de origen" ${ }^{60}$.

En 1582 se interpone pleito por parte de la Corona a Bartolomé de Amaya, propietario de parte del territorio de la antigua alquería de Pereila, por la usurpación de tierras reales. Vemos como todavía se conservan parte de los términos de finales del siglo XV, lo que puede indicarnos la existencia de unos límites propios heredados de época islámica:

Bartolome de Amaya vecino de Coyn se le pone demanda por las tierras que poseía en Coyn en el partido de Pereyla se le delinda y determina que comenzaba por una punta lindando con el arroyo de Valdeperales y por la cabeçada por los Espartales y monte realengo y por el otro cabo con la senda que va a Pereyla que sale del camino que va a Monda y de allí al cerro de las Lombardas... ${ }^{61}$

Hay que recalcar la alusión que se hace en el Pleito por parte de cuatro testigos a la existencia de un amojonamiento artificial del territorio de Pereila al final del emirato nazarí: “...el dicho lugar de Pereyla en tienpo de moros tenía un termino aparte e amojonado por sy..." ${ }^{\prime 2}$ y que dicho amojonamiento se vuelve a restituir por su nuevo propietario, Pedro de Barrionuevo, ya a finales del siglo XV: “...Pedro de Barrionuevo el biejo tomo la dicha Pereyla tornaron a echar los mojones el dicho Barrionuevo por donde yvan quando era de moros..." ${ }^{33}$ Es probable que se tratara de una información pretensiosa e interesada por parte del Cabildo con la intención de obtener una delimitación bien marcada y sobre cuyo trazado no cupieran dudas. Así algunos investigadores que han estudiado los términos de las alquerías, en concreto Trillo San José, afirman que estos límites artificiales no existían en estos asentamientos:

...las alquerías no tenían un territorio definido ni cerrado, tampoco estaba delimitado con hitos construidos para ello [...] Los términos de estos asentamientos no estaban marcados por señales construidas a tal efecto sino por referencias geográficas tales como de sierra, barrancos, arboles... ${ }^{64}$.

Sin embargo planteamos la hipótesis de que en esta zona, determinados territorios sí podrían haber estado delimitados con hitos artificiales. El argumento que esgrimimos es que el distrito de Dakwan (Coín) ${ }^{65}$ estaba densamente poblado entre los siglos XIV y XV

${ }^{60}$ Trillo SAn José, El agua en al-Andalus, p. 56.

${ }^{61}$ AMM, Vol. 123, Libro de Composición de Tierras, fol. 153.

${ }^{62}$ ACM, Pleito.

${ }^{63}$ Ibidem. Igualmente existe diversa documentación que parece indicarnos la existencia de estos mojones, en concreto una real cédula de 1490, apenas cinco años después de la caída de Dakwan: “...que al tiempo de medir mydiose las tierras de Xubrique que después las de Pereyla començando desde el mojon de Monda y Pereyla...” (ACM, Pleito).

${ }^{64}$ Trillo SAn José, El agua en al-Andalus, p.55.

${ }^{65}$ Sobre la formación de los distritos castrales es pionera la obra de BAZZANA, CREsSIER, y Guichard, Les chăteaux ruraux d'al-Andalus. Para la zona objeto de nuestro estudio Martínez Enamorado señala que durante la fitna hafsūni se observa en el valle medio del Guadalhorce:"...unas pautas de ocupación del territorio en las que se señala la creación temprana de distritos que rigen los territorios campesinos circundantes..." destacando 
debido a la existencia de recursos hídricos abundantes que generaron una rica agricultura de irrigación. Así tenemos el río del Nacimiento que proporcionaba aporte hídrico a las tierras de Benamaquis ${ }^{66}$, Dakwan y Valdeperales (Pereila); y la fuente de la Reina que lo suministraba a Pereila Alta, ambos asentamientos en el término municipal de Coin. Limítrofe con Benamaquis ${ }^{67}$ y Pereyla ${ }^{68}$ estaba la alquería de Jubrique ${ }^{69}$ cuyo suministro hidráulico provenía del manantial de las Torres.

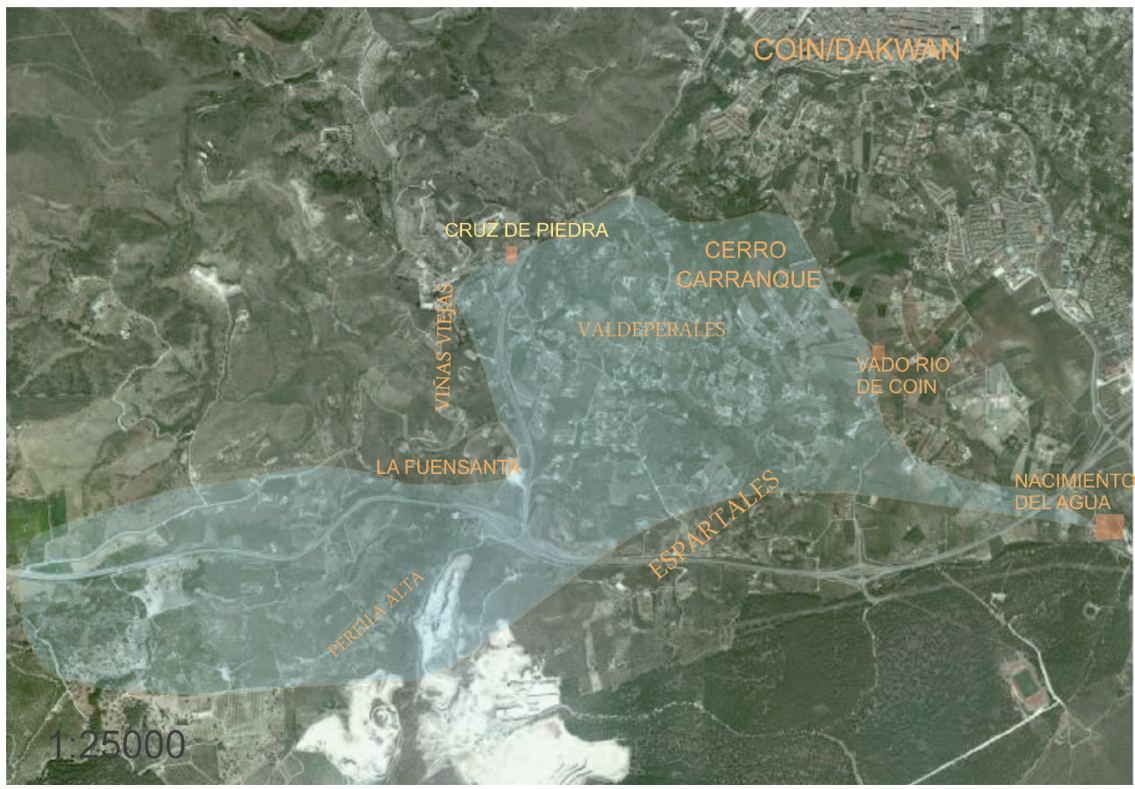

Fig. 2. Perímetro territorial de la alquería.

entre ellos “hisn qaštruh Dakwān/Coín”. Martínez Enamorado, Al-Andalus desde la periferia, p. 582. También en fuentes árabes se menciona la existencia de un distrito castral cuya capitalidad ostentaba Dakwan: ...le nombra comandante de los voluntarios de la fe, combatientes de la guerra santa, y primer jefe para la defensa de la religión en la ciudad de Málaga, hermana de la capital de su reino, segunda perla preciosa de su collar [...] confiándole el cuidado de los distritos occidentales, Ronda y Dakwan y sus términos de un modo exclusivo e independiente, con amplio e ilimitado poder para conducir a todos ellos hacia la guerra santa, obrando según su gloria en toda situación..." Ahmad Mujtar AL-ABBADI, "Muhammad V Al-Gani Bi-1lah, rey de Granada”, p.32.

66 Sobre la alquería de Benamaquís se ha publicado recientemente un trabajo realizado por Marmolejo Cantos en que ubica dicho poblamiento en la actual urbanización de Miravalle en término de Coín, además sus tierras eran regadas con las aguas del río Nacimiento mediante "...las acequias de la Candonga y del Naranjal suministraban agua al castillo y a los bancales de Benamaquis...” Marmolejo CANTos, El castillo de Benamaquís, p.41.

67 "En una piedra questan en un llano que llaman de Xubric y en arábigo se dice Almahaden donde dixeron que parten los términos entre Xubric e Benamaquis y de allí va el dicho término por el monte adelante a dar una sierra que se dice Ally Natar donde están dos matas que por ser monte no se llega a ellas.." BEJARANO RoBles, Libro de Repartimiento de Málaga, III, p.403.

${ }^{68}$ Aunque coincidimos con Marmolejo Cantos en los límites entre Benamaquis y Pereila, pensamos que son incompletos ya que también se establecerían lindes entre ambas alquerías en la zona de la surgencia del río Nacimiento y en una franja al sur del llano de Matagallar: "Hacia el Oeste bien pudo lindar con la alquería de Pereila en la cara sur del cerro Carranque, también llamado de las Lombardas, pues la alquería de Pereila extendía sus dominios hasta Valdeperales.." Marmolejo CANTos, El castillo de Benamaquís, p. 26.

${ }^{69}$ La alquería de Jubrique y sus tierras fueron distribuidas en el Repartimiento de 1492 entre las villas de Coín y Alhahurín el Grande. Bejarano PÉrez, Los Repartimientos de Málaga IV, 2004. 


\section{LOS DIFERENTES USOS DEL TERRITORIO: ÁREAS DE TRABAJO Y ESPACIO RESIDENCIAL}

Siguiendo a Trillo San José “...cada alquería ocuparía una de estas áreas cerradas explotables y bien delimitadas, dividiendo conceptualmente el espacio en función del tipo de productividad que se podía extraer de la misma"70. Estos mismos principios los podemos aplicar a las zonas productivas de Pereila en que la documentación recogida en el Pleito y en los diversos protocolos notariales del siglo XVI, muestran la evolución de estos espacios en cuanto a tipos de cultivos, propietarios y arrendatarios, evolución que abarcará desde finales del período musulmán hasta la expulsión de los moriscos de la comarca ya en 1568 .

No todos los espacios productivos reciben la misma atención, y serán aquellos sectores que tengan un mayor interés para las partes implicadas en el Pleito, sobre los que se hagan mayor hincapié.

La fundación de dicha alquería estuvo íntimamente ligada con la fuente de la Rey$\mathrm{na}^{71} \mathrm{y}$ con los espacios de cultivo que sus aguas generaron, ya que: "Las posibilidades hidráulicas fueron, en todos los casos, el factor determinante..." el núcleo económico y residencial de este ente poblacional y territorial, y correspondería con el actual partido rural de Pereila Alta. Este núcleo original estaba formado por espacios de irrigación, olivares y viñas, además de la única zona residencial conocida. La información que transmiten las fuentes documentales son escasas y poco esclarecedoras. Sobre la zona de cultivo hay algunas alusiones a finales del siglo XV: “...ay algunos naranjos e morales e azeytunos e otros arboles frutales e viñas [...] que algunos vezinos ansy de la villa de Cohin como Alaurin con poco temor de nuestra justicia an cortado çiertos naranjos e azeytunos e morales e perales e viñas..." ${ }^{\text {"73 }}$. Igualmente se mencionan "...tres arançadas de tierra de riego que avian quedado vacante cabe el rio Pereila..." y que se le concedieron a Francisco Pallarés. También se especifican algunos sectores de viñas: "Y quedan de la otra parte del ryo de Pereyla de un cabo e de otro fasta doze aranzadas de viñas que tenia el alcayde de Monda encima de las huertas" $" 74$.

Dada la falta de información documental precisa que nos permita la identificación de los espacios de cultivos de irrigación y de la zona residencial, vamos a aplicar los principios metodológicos de la arqueología hidráulica y de la arqueología del paisaje o extensiva.

La arqueología hidráulica “...constituye un procedimiento para estudiar espacios irrigados, donde la canalización y transporte del agua implica unos límites habitual-

${ }^{70}$ Trillo SAN José, El agua en Al-Andalus, p.151.

${ }^{71}$ Los sistemas de irrigación de origen andalusí obtenían el suministro hídrico de pequeños cursos fluviales y de fuentes. Posteriormente, ya en época contemporánea, comenzaron a aprovecharse los ríos de forma generalizada para el riego:"'Las huertas de la comarca (Guadalhorce) se concentran en torno a las aguas de los pequeños cursos que nacen en los Rondaides y Sierra de Mijas..."López de Coca Castañer, La tierra de Málaga a finales del siglo XV, p. 38.

${ }^{72}$ Trillo SAN José, El agua en al-Andalus, p. 151-152.

${ }^{73}$ AGS, Registro General del Sello, IV-1490- f.50.

${ }^{74}$ Bejarano Pérez, Los Repartimientos de Málaga IV, p.246. 
mente rígidos y fácilmente identificables de los parcelarios" ${ }^{75}$. Sus principios se están aplicando, para los espacios irrigados de origen andalusí, en las islas Baleares, País Valenciano, Murcia y Andalucía Oriental ${ }^{76}$. Con la misma metodología se están realizando diversos trabajos en las huertas de Casarabonela y el valle del Genal por parte de Félix Retamero y Virgilio Martínez Enamorado, y en determinadas zonas de la subcuenca de río Grande, investigaciones que se están llevado a cabo por Esteban López García y por Antonio Ordóñez Frías. Todos estos últimos espacios hidráulicos situados en la Provincia de Málaga.

La arqueología del paisaje se basa en “...el reconocimiento de la huella de la sociedades humanas en el paisaje [...] atiende al estudio de la ocupación del espacio y su organización por parte de los hombres a lo largo de la historia" ${ }^{\text {". }}$. Mediante la prospección superficial del terreno y el recurso a las fuentes escritas se establecerán una serie de pautas sobre las transformaciones que ha sufrido el paisaje y las culturas que los modificaron.

\subsection{LOS DIVERSOS SISTEMAS DE IRRIGACIÓN DE PEREILA ALTA}

Vamos a realizar el estudio de las acequias que riegan el partido de Pereila Alta con el objetivo de diferenciar los trazados que pudieran tener un origen andalusí, de aquellas ampliaciones o nuevas construcciones posteriores ${ }^{78}$, y así, también, aproximarnos a la superficie regada de finales del siglo $\mathrm{XV}^{79}$. Según el origen de su suministro hídrico podemos dividir los sistemas hidráulicos en tres; la acequia de la fuente de la Reyna, la acequia de la fuente de la Alfaguara y las acequias de río Pereila.

La acequia de la fuente de la Reyna tenía su toma en el manantial de la Reyna ${ }^{80}$, punto de captación que estaba apenas a cinco metros del cauce de río Pereila ${ }^{81}$. Discu-

75 Ballesteros Arias, Kirchner, Fernández Mier, Ortega Ortega, Quirós Castillo, Retamero, Sitjes, Torró y Vigil-EsCALERA Guirado, "Por una arqueología agraria de las sociedades medievales hispánicas", p. 189.

${ }^{76}$ Pioneros en esta metodología han sido Miquel Barceló, Helena Kirchner, Carlos Navarro y Félix Retamero por la Universidad de Barcelona; Enric Guinot Rodríguez, relacionados con la Universidad de Valencia; Antonio Malpica Cuello y Carmen Trillo San José, vinculados a la Universidad de Granada.

77 Malpica Cuello, "El estudio del paisaje y la práctica de la arqueología del paisaje”, p. 25.

${ }^{78}$ Una de las primeras iniciativas en establecer las secuencias de transformaciones del regadío andalusí al medieval es la obra: Bazzana y Meleumeester, "Irrigations systems of islamic", pp. 152-160.

${ }^{79}$ Kirchner y Navarro, “Objetivos, métodos y práctica de Arqueología hidráulica”, pp. 159-182.

${ }^{80}$ Debido a las explotaciones de canteras en la zona el nivel freático ha sido modificado y la fuente de la Reyna ha dejado de emanar agua de forma natural, por lo que ha sido necesario la construcción de un pozo cuyo caudal se obtiene mediante motores eléctricos.

${ }^{81}$ Justo por encima de la fuente de la Reyna, a río Pereila se le denomina río de Abuquería. Según F. Glick: "...un río que nace en zona de montaña y termina atravesando una llanura, se organiza hidráulicamente como si fuese otro río distinto. Hasta el nombre del río puede cambiarse, si pasa del dominio de una tribu al de otra". GLICK, "El sentido arqueológico de las instituciones hidráulicas", p. 167. En el partido rural de Albuqueria existía un poblamiento de origen andalusí que estaba a un kilómetro río arriba, el cual también tenía su área de irrigación cuyo suministro hídrico provenía del arroyo del Lobo. Ejemplo similar encontramos en Monda en el arroyo Alpujata cuyo tramo superior se denomina con dicho topónimo, mientras que en su tramo medio se le llama Alcazarí. OrdóÑEz FríAS, "Los sistemas de irrigación en el pago de Alpujata-Monda- (Málaga)", . 
rre por la margen izquierda del río y tiene una longitud aproximada de 500 metros $^{82}$, regando de forma continua, prácticamente desde su punto de captación, una superficie de $3,4 \mathrm{Ha}^{83}$. Como sistema de vertiente que es ${ }^{84}$, su estructura está constituida por un canal principal de distribución y por seis brazales o acequias secundarias que se encargan de la distribución del agua a aquellas zonas que no están colindante con la acequia madre. El trazado de estos brazales es irregular formando una trama tipo arborescente, trazado que se diseñó de forma oblicua a las curvas de nivel para evitar que alcanzaran un grado de inclinación excesivo con los consecuentes problemas de erosión que ello podría acarrear. Dos arroyos tiene que salvar dicha acequia madre, problema que se resolvió con la creación de pequeños acueductos. Sin embargo cuando los brazales secundarios encuentran estos obstáculos no los cruzan corriendo paralelos a ellos. Estos arroyos también podrían haberse utilizados como desagüe del sistema.

Pensamos que con la entrada del grupo que diseño y construyo esta zona irrigada ${ }^{85}$ se generaron unos espacios de trabajo totalmente nuevos a los existentes con anterioridad. El nuevo parcelario se caracterizó por qué su construcción estuvo supeditada por una serie de condicionantes entre los que destacamos el trazado del río, que en su acción erosiva creó una serie de meandros, así como por el grado de inclinación del terreno. Como solía ser habitual la construcción de las diversas terrazas iba de abajo a arriba ${ }^{86}$.Por lo tanto dichos meandros y su morfología cóncava o convexa, determinaron el arranque de las terrazas de riego y, por consiguiente, condicionan también el resto de la estructura parcelaria. Lo podemos dividir en tres sectores:

-El sector primero está delimitado en su base por un meandro de forma cóncava poco marcado. Se creó una primera terraza o bancal-base de una cierta amplitud, con forma poligonal parecida a un rectángulo y que tendría una extensión de 140 metros de largo por 80 metros de ancho. Una vez que el terreno comienza a tomar un grado de inclinación acusado, se realizan seis terrazas que irán disminuyendo, de abajo a arriba, en cuanto a su anchura, con 10, 6, 6, 5, 5 y 4 metros respectivamente, y sin que existan entre ellas un desnivel superior a un metro.

-El Sector segundo coincide, en su parte inferior, con un amplio meandro de forma convexa, teniendo una superficie de riego sensiblemente mayor que el sector anterior. También se creó un bancal-base de proporciones similares al del primer sector con un

${ }^{82}$ Clasificamos como "acequia de la fuente de la Reyna" aquel canal que va desde la surgencia del mismo nombre, hasta el arroyo de Ballonato, ya que interpretamos que a partir de ahí fue una ampliación de época moderna y no se incluiría dentro de las estructuras de origen andalusí.

${ }^{83}$ Carmen Navarro establece una diferenciación entre "...la extensión de los perímetros antiguos, que en ningún caso superaban las 5 Ha y oscilan entre 3 y $4 \mathrm{Ha}$, mientras que la nueva huerta supera las 9 Ha...” Navarro, "El tamaño de los sistemas hidráulicos".

84 "La organización del espacio irrigado en una sola vertiente hace que sean necesarias acequias secundarias o ramales que conduzcan el agua a las parcelas que no tengan acceso directo desde la acequia principal". KIRCHNER, "Redes de asentamientos andalusíes en Mallorca", p. 84.

85 Según Martínez Enamorado la fundación de estas alquerías "...vendría de la mano de la instalación de los grupos tribales beréberes de la primera ola, repartidos por las áreas montañosa de la Algarbía malagueña”. Martínez Enamorado, Al-Andalus desde la periferia, p. 585.

86 "Los diseños, complejos y enormes, de terrazas irrigadas de los Andes centrales, de Perú y de México compartan idénticas características que los esquemas magrebíes y andalusíes por lo que hace a su forma de construirlos de abajo a arriba..." BARCELó, "El diseño de los espacios irrigado", p. 32. 
segundo bancal que alcanza unas proporciones de 80 metros de largo por 20 metros de ancho. A continuación se construyeron cuatro terrazas, cuyas alineaciones coinciden con los cuatro últimos bancales del sector primero.

-El tercer sector tiene su base sobre un pronunciado meandro cóncavo que ha provocado una intensa erosión del cauce del río sobre la margen izquierda de este. Por lo tanto los primeros siete bancales que se construyen son estrechos y van aumentando de anchura a medida que van subiendo la vertiente $(5,3,6,5,7,8$ y 9 metros respectivamente) debido a la paulatina disminución del grado de inclinación del terreno. Condicionado por la existencia de un pequeño paleocauce, lindero con las terrazas más cercanas al río, se creó un bancal de forma trapezoidal de 30 metros de ancho por unos 20 metros de largo que añade un cierto grado de irregularidad al conjunto. La parte superior de la vertiente es coronada por otra terraza de forma casi cuadrada de 44 metros de ancha por 40 metros de larga que alinda, por arriba, con la acequia madre. Como vemos forma un sector algo más compartimentado e irregular que los anteriores, pero sin perder la unidad estructural del conjunto.

El sistema de la fuente de la Reyna presenta, en todos sus sectores, una uniformidad que denota que su construcción se realizó en un período de tiempo relativamente corto y probablemente por el mismo grupo humano. Otra característica destacable es la mesura, el equilibrio que observamos en el sistema con una acequia madre que no sobrepasa en ningún momento el 3\% de inclinación y un desnivel total, desde su toma hasta su desagüe en el arroyo de Ballonato, de unos 12 metros negativos, además de su estructura parcelaria que supo aprovechar los desniveles del terreno con gran maestría en que destaca su equilibrada proporcionalidad y una homogeneidad que nos lleva a pensar que fue fruto de un proyecto común de estas sociedades campesinas. Este saber muestra la madurez, el bagaje en la construcción de sistemas hidráulicos que contrasta notoriamente con las ampliaciones que sufrió dicha acequia en el período moderno.

A partir del arroyo de Ballonato, la acequia de la fuente de la Reyna discurre por un sector en que el terreno toma un grado de inclinación muy acusado, desapareciendo las terrazas de cultivo durante un trayecto de al menos cien metros, para luego virar hacia el oeste y alejarse de la vertiente izquierda del río, suministrando agua a una serie de terrazas en que el grado de pendiente va disminuyendo paulatinamente y con bancales que decrecen en anchura a medida que desciende por la ladera, ya orientada hacia la zona por donde discurre el camino real de Coín a Monda, es decir al noroeste. Este nuevo tramo de acequia tiene una longitud de 220 metros y riega una superficie de unas 6,5 Ha. Lo consideramos ya una ampliación posandalusí dado que se produce una ruptura orográfica y geográfica con respecto a la unidad que mantenía la fuente de la Reyna. Es decir que la sensación de discontinuidad es evidente. Pero también se observa entre ellos diferencias estructurales. El tramo de acequia de probable origen andalusí posee una configuración arborescente en su interior, con los diversos brazales secundarios que tienden a la irregularidad, además de tener un perímetro de forma piriforme ${ }^{87}$. Sin embargo en la ampliación que consideramos moderna los brazales secundarios están distribuidos con una traza perpendicular con respecto a la acequia madre, es decir con una trama de tipo "peine", además de poseer un perímetro de forma ortogonal.

${ }^{87}$ Guinot Rodríguez, "El paisaje de la huerta de Valencia”, pp. 98-111. 
Ambos son el reflejo de dos grupos humanos con estructuras sociales y productivas diferentes.

Apenas cincuenta metros por debajo de los espacios de cultivo de la fuente de la Reyna y en la misma margen del río, se desprende la acequia de los Molinos que tiene su toma en un azud en el mismo cauce del río. Parece que su construcción tuvo como motivo prioritario suministrar agua a los molinos de la Pasada y de En medio, en funcionamiento desde, al menos, los años finales del XV, y posteriormente, en época contemporánea, la del molino de Bartolomé Moya, conocido también como del Azúcar. La acequia tiene una trayectoria que discurre paralela al cauce del río, en que el desnivel entre ambos se va adquiriendo de forma casi imperceptible y con una separación acequia-río que generalmente no supera los 5 metros. Por lo tanto los espacios de irrigación son muy escasos y se concentran entre los molinos de En medio y la Pasada ${ }^{88}$, y por debajo de este último, no superando, en total, la hectárea. Dichas instalaciones, debido a los escasos desniveles que posee la acequia, se situaron en sendos escalones producidos por los efectos de la erosión selectiva del cauce sobre sustratos calizos más blandos que los circundantes. Discurre durante un trayecto de 560 metros, y tanto el sistema hídrico, como el molino de En medio y la Pasada parecen tener un origen andalusí:

Otro sy es nuestra merced e voluntad que Rodrigo de Alcazar nuestro guarda vesino de la dicha ciudad de Malaga haya e tenga por merced para siempre jamás que el ha tenido e poseydo e tiene e posee hasta aquí que an la dicha ciudad cerca de las casas donde el mora un sytio de molino de los dos citios que están en el ryo de Pereyla el mejor que el escoja para que haga de ello lo que quisyere e por bien toviera... ${ }^{89}$.

También tenemos información de que Rodrigo Alcázar escogió el molino de la Pasada, es decir aquel que estaba más cercano al camino real de Coín a Monda:

...todo esto queda a mano izquierda por Pereyla salvo el molino de Rodrigo de Alcaçar con sus bancales y pasado el rio del molino hacia Monda hasta llegar atierras de la Fuensanta ${ }^{90}$.

Vemos como en 1572 se recogen ya tres molinos en Pereila, estando todos ellos identificados en la actualidad. El primero o de Bartolomé Moya ocupaba la posición más alta y parece tener su origen en la primera mitad del siglo XVI. El segundo o de En medio, a continuación de este, aprovechando un marcado escalón que hace el río. El tercero, o dela Pasada, está junto al camino real de Coín a Monda pero ya en la margen derecha del río:

...que ai dos molinos de pan con cada dos paradas que son quatro por todas, en el rio de Pereila jurisdizión de Málaga en la dezmeria de la villa de Coin, el uno de ellos

88 “....una huerta mya que yo tengo que dizen Pereyla toda quella y mas un tablero myo que yo tengo y esta encima de un molino como vamos a Pereyla...” AHPM, P-6598, s/f, 1551.

${ }^{89}$ AMM, AACC, Vol. 1, fol.3, 1489.

90 ACM, Pleito. 
es de Batolomé Arruro, [...] el qual dicho molino es el que está en medio de uno de Bartolomé de Moia chistiano viejo bezino de Coin... ${ }^{91}$.

La conducción del agua al molino de la Pasada se realiza mediante un acueducto que parte del molino de En medio y cruza a la margen derecha del río donde una acequia de unos 70 metros de longitud conecta con dicha instalación. Parece que esta conducción, junto con la ampliación de un cárcavo, fue consecuencia de una reforma realizada en 1541:

...un molino de pan que el señor Juan de Liza tiene en el rio de Pereyra entre Coyn y Monda junto a la pasada del camino [...] que se han de hacer dos paradas en el dicho molino para las cuales se ha de alzar el herido sobre lo que agora está media vara de medir"92.

La acequia de la fuente de la Alfaguara ${ }^{93}$ tiene su toma en el manantial del mismo nombre, en las cercanías del camino real que va de Coín a Monda y por lo tanto en un sector diferente, aunque cercano, a la vertiente izquierda de río Pereila. Su canal de conducción posee un recorrido de 900 metros hasta llevar a la zona de cultivo que coincide, parcialmente, con los terrenos que franquean la parte superior de la acequia de la fuente de la Reyna, regando unas 0,6 Ha aproximadamente. También consideramos a este sistema como posterior al de la fuente de la Reyna, con una desproporcionalidad notoria entre la longitud de la acequia y los espacios irrigados.

En la margen derecha del río se sitúa la acequia de la Umbría cuyo aporte hídrico toma directamente del cauce mediante un azud, unos 100 metros por debajo de la surgencia de la fuente de Reyna pero en márgenes diferentes. Igual que el anterior, es un sistema de vertiente aunque con una cierta desarticulación en cuanto a los espacios irrigados que no se reparten de forma proporcionada. Tiene una longitud total de 1200 metro cubriendo una superficie de riego aproximada de 2,8 Ha. Posee un molino hidráulico paralelo al azud de la acequia de los Molinos denominado de Jiménez ${ }^{94}$. Ya tenemos constancia de la existencia de riegos en la margen derecha de río Pereila sobre 1564, pero carecemos de datos suficientes para saber si su fundación corresponde con el Medievo o tiene un origen moderno:

...las rozas y tableros que yo tenya arendado a Juan de Almodovar que son en termynos de Pereyla quitando dellos las rozas que la rendado a Diego Go-

${ }^{91}$ Urbano PÉrez, La villa de Monda en el siglo XV, pp.166-167.

92 AHPM, P-6598, 1541, s/f.

${ }^{93}$ En la actualidad dicha fuente y acequia son prácticamente irreconocibles debido al aterrazamiento que ha sufrido el terreno. Hoy día la extracción del agua se realiza mediante motores eléctricos en varios pozos cercanos al área de cultivo.

${ }^{94}$ Como ya hemos visto anteriormente dicho molino no figura entre los mencionados a finales del siglo XV ni entre los del Apeo de Monda de 1572. Tampoco se recoge en el Catastro de Ensenada cuando se dice: "Y los cuatro siguientes son los que están situados en el río de Pereila siendo primero el molino nombrado del Azúcar [...] Otro de dos paradas nombrado de Fernán Sánchez [...] Otro nombrado molino de la Puente". AGS, CE, RG, L. 285, fols. 67v y 68v. Vemos como en la actual Pereila Alta, según el Catastro, solo existían tres molinos (el de la Puente está en el puente de la Ermita, algo más abajo que la zona estudiada), por lo tanto el molino de la acequia de la Umbría tuvo que ser posterior a estas fechas. 
mez Portugues y en lugar desta dicha roza le doy los tableros que yo el dicho Bartolomé de Amaya tengo desta parte del río hacia Coyn... ${ }^{95}$.

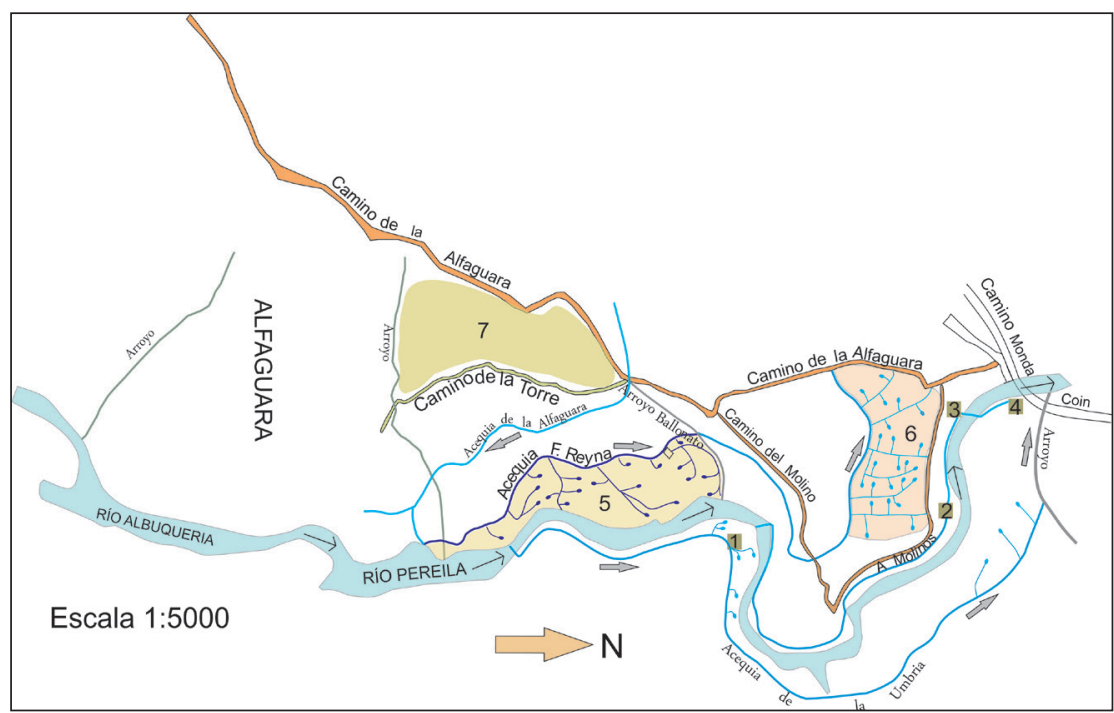

Fig. 3. Hidráulica de Pereila Alta. 1. Molino de Jiménez, 2. Molino del Azúcar, 3. Molino de En medio, 4. Molino de la Pasada, 5. Acequia F. de la Reyna: sector de origen andalusí, 6. Acequia F. de la Reyna: ampliación moderna, 7. Espacio residencial.

Hay que señalar que los molinos hidráulicos de origen andalusí no solamente no estaban integrados en el sistema de irrigación principal o de la fuente de la Reyna, sino que además tampoco utilizaban el mismo suministro hídrico, ya que dichas instalaciones se abastecían del río, mientras que el de la fuente de la Reyna lo hacía de la surgencia del mismo nombre. Fue una solución que priorizó el riego sobre la molienda con la originalidad de que ambos sistemas eran independientes ${ }^{96}$. También tenemos que tener en cuenta que durante el siglo XVI la molinería en la zona sufre importantes transformaciones como consecuencia de los cambios sociales y económicos producidos tras la conquista castellana y que tiene su expresión en el aumento de número de cárcavos (generalmente de uno a dos), la ampliación de las instalaciones preexistentes, la construcción de nuevos molinos y la priorización de la molienda sobre la irrigación ${ }^{97}$.

95 AHPM, P-6554, s/f, 1564.

${ }^{96}$ Los estudios realizados sobre sistema de irrigación andalusíes en que existían molinos hidráulicos, sobre todo en las islas Baleares, han demostrado que la irrigación tenía prioridad sobre la molienda y los molinos se situaban al final de los sistemas de riego para no interferir en ellos. Argemi Relat, "Glosario de términos hidráulicos, 1995, p.173.

${ }^{97}$ Los molinos de la Pasada, de En medio, de Moya y de Jiménez, poseían ya a mediados del siglo XVI dos cárcavos. En el caso del molino de la Pasada la documentación escrita recoge la fecha de las ampliaciones tanto en el número de cárcavos, como en la creación de diversas dependencias (AHPM, P-6598, 1541, s/f). Los molinos de origen posmedieval en Pereila son del Americano, "la Puente", de Ortiz y el de Jiménez. Es curioso como este último, cuando realizaba la molienda, vertía el agua directamente al río y por lo tanto no tenía un aprovechamiento en las zonas de irrigación que había por debajo de dicho molino. 


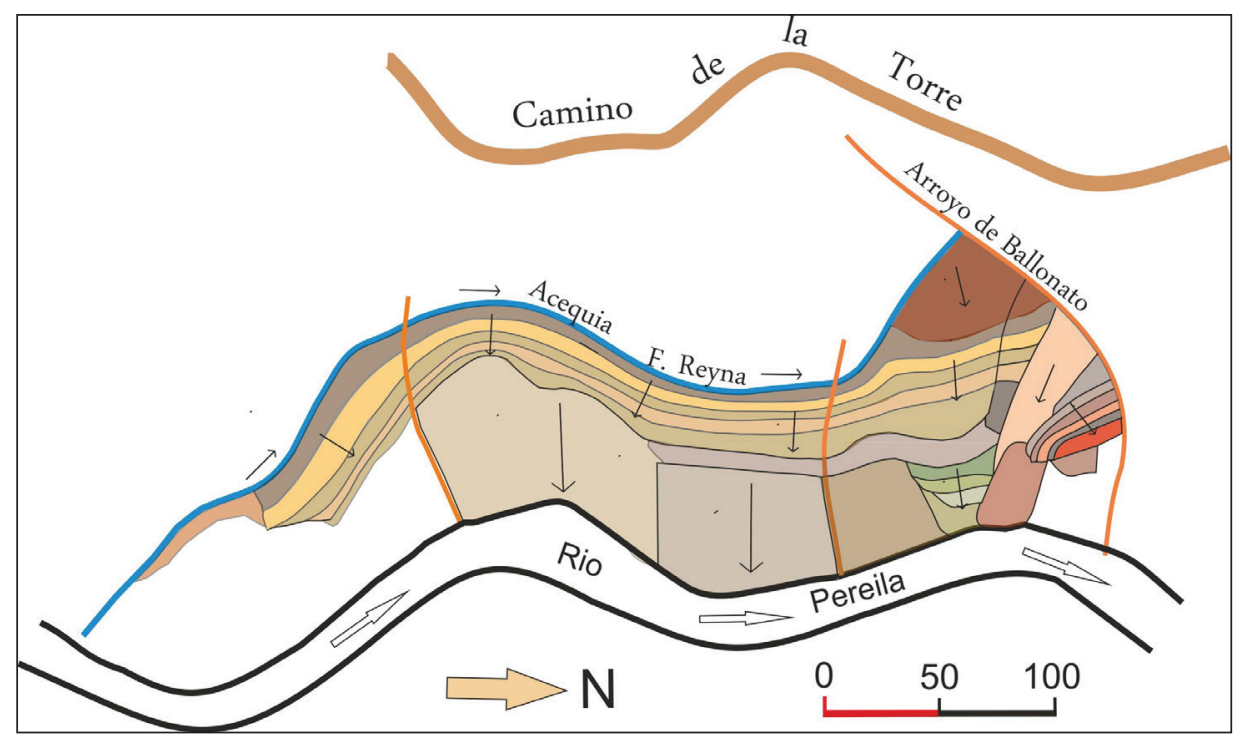

Fig. 4. El aterrazamiento y su estructura en los espacios irrigados de la fuente de la Reyna.

\subsection{EL ESPACIO RESIDENCIAL}

Si la información que posemos sobre el principal núcleo de irrigación de probable origen andalusí es escasa, menor aún es la relacionada con los espacios residenciales. Es interesante la referencia que se hace a finales del siglo XV, indicándonos que hubo un espacio de hábitat que parece que fue ex novo: "E nos teneis en los dichos heredamientos podeys edificar e faser casas para vuestro aposentamiento e para vuestros renteros con tanto que sean casas llanas de aposentamiento e no fuerte..." ${ }^{\text {98 }}$. Esta construcción de nuevas viviendas nos hace pensar que los antiguos habitáculos de origen andalusí habían sido destruidos o estaban inhabitables ya a finales del siglo XV. La causa podía estar relacionada con las continuas cabalgadas que los castellanos realizaban en la comarca, especialmente durante el siglo XV. Magnífico testimonio lo trasmite Juan Albyte, testigo del Cabildo, cuando dice:

...que este testigo tiene memoria del dicho lugar de Pereyla desde que hera nyño porque en tienpos de moros moravan su padre y madre en Pereyla y quando entro una partida llamada Pernya con los cristianos y la rrobo e este testigo huyo a Coyn...99.

Son frecuentes, también, las alusiones que se hacen a determinados habitáculos en los protocolos notariales de mediados del siglo XVI, y que nos sugieren que había un espacio de hábitat concentrado, aunque no sabemos si correspondía con el antiguo

98 AGS, Cedula de la Cámara, Libro 1, fol. 76, 1493.

99 ACM, Pleito. 
espacio residencial de origen andalusí: “...una casa que es en Pereila linde con casa en que vive Albaro Buzeyte y con casa de Juan Alrulquy..." ${ }^{100}$.

Sobre el número de residentes y por lo tanto del hipotético tamaño del espacio de hábitat, tenemos algunos datos: “...que este testigo tiene el lugar de Pereyla por lugar de morisco porque ha mas de treinta años que vido morar en la obra de diez e ocho o veynte vecinos morisco [...] el dicho lugar de Pereyla tenya treynta vecinos poco mas o menos..."101. A pesar del interés que posee esta información no la consideramos válida para evaluar la población que podría tener la alquería en el período tardonazarí, debido a que se despobló por la acción de una cabalgada y que posteriormente, posiblemente a finales del siglo XV, se repobló con renteros mudéjares por parte de Pedro de Barrionuevo ${ }^{102}$ : “...estaba la dicha Pereyla despoblada de vecinos Barrionuevo la poblo de morisco moros exactamente fueron veynte..." 103 por lo que a pesar de que la elección del número de pobladores seguramente estuvo relacionada con el volumen de los espacios productivos existentes, este no coincidiría con el de la época islámica, fundamentalmente por tratarse de dos sistemas socio-económicos con notables diferencias. Además ya a principios del XVI uno de los territorios más productivos de la alquería, como fue Valdeperales, estaba en manos de arrendatarios cristianos viejos y fuera de la órbita económica de Pereila.

No poseemos testimonios documentales que aporten información sobre la ubicación del espacio de hábitat por lo que, para su localización, hemos utilizado la técnica de prospección superficial denominada "estrategia de cobertura total"104 con un barrido sistemático del terreno. Se eligió una cuadrícula que forma un ángulo entre los caminos de la Torre y de la Alfaguara, por encima de la línea de rigidez ${ }^{105}$ que marca la acequia de la fuente de la Reyna, y en un sector en que el grado de pendiente del terreno se modera ${ }^{106}$. Los resultados fueron la aparición de abundantes fragmentos cerámicos que corresponden, en su mayoría, con tipologías y decoraciones relacionadas con el Bajo Medievo. Existe una gradación en cuanto a la concentración de estos restos, siendo más frecuentes en la parte media y baja de la ladera disminuyendo de forma drástica a medida que nos acercamos a la acequia, por abajo, y al camino de la Alfaguara, por arriba. El espacio residencial estaba situado en una ladera, cuando el grado de inclinación se va suavizando y delimitado por dos viales que vertebraban el terreno; el camino de Pereila o de la Torre, ramal que derivaba del camino real de Coín a Monda, y el camino de la Alfaguara, que comunicaba la alquería de Pereila

${ }^{100}$ AHPM, P-6548, s/f, 1553.

101 ACM, Pleito.

${ }^{102}$ Cabrillana opina que la entrada de nuevos renteros moriscos en Pereila es la consecuencia de una fiscalía abusiva “...los abusos de los recaudadores de impuestos, tanto civiles como eclesiásticos” Cabrillana, El problema de la tierra en Málaga, p. 122.

103 ACM, Pleito.

104 García SANJUÁn, Introducción al reconocimiento y análisis arqueológico, p. 71.

105 Se denomina "línea de rigidez" a las acequia-madre cuyo trazado permanece generalmente inalterable a través del tiempo, ya que su modificación supondría cambios sustanciales en todo el sistema de irrigación. Kirchner, Helena y NaVArro, "El diseño de espacios irrigados en al-Andalus", p. 58.

106 Agradecer a Rafael Cárdenas Márquez y Andrés Cárdena la colaboración prestada al autorizar la prospección de sus fincas donde se han encontrado los indicios de la existencia de la alquería de Pereila y de la torre asociada a ella. 
con el partido rural de Alpujata y la alquería de los Villares de Alpujata ${ }^{107}$, ambos lugares en el actual termino municipal de Monda. Estimamos que el espacio residencial tenía una superficie aproximada de $2 \mathrm{Ha}$. Además poseía una serie de características topográficas que se repiten en la mayoría de los espacios residenciales del período Bajomedieval en la comarca. Se situaba en una ladera, cuando ya la pendiente comienza a suavizarse. En su vertiente sureste estaba franqueada por el cangilón del cauce del río, accidente natural que dificulta el acceso al poblamiento desde el sector de las huertas. Al noroeste existe lo que hemos denominado "espaldar" o elevación que cae de forma abrupta hacia el camino real de Coín a Monda, y por los laterales la delimitaban dos arroyos poco marcados.

Sabemos, por testimonios documentales, que también existía una torre-alquería:

Por quanto vos Pedro de Barrionuevo, alcayde del Burgo nos feziste relaçion que vos teneis dos heredamientos çinco leguas de Malaga que se llaman Pereyla y Xulique en las quales con nuestra licencia reparasteis dos torres que allí están... ${ }^{108}$.

Y que sobre las dichas torres había propuesta de derribo por parte de la Corona, que finalmente no se ejecutó: “...Pereyla y Xubrique que son dos torres cerca de Coyn tienelas Pedro de Barrionuevo dice que por merced conviene que se derriben" 109 . Igualmente existe referencia sobre esta edificación a mediados siglo XIX:

Pereira es otro monte aislado en la misma dirección, de $3 / 4$ de leguas de circuito, en cuyo punto hubo un despoblado morisco del mismo nombre cuyas torres se conservan aún en el paraje titulado Torre de D Fernando... ${ }^{110}$.

El topónimo de "camino de la torre" figura en las escrituras de determinados propietarios actuales de Pereila Alta, cuyas tierras lindan con dicho camino ${ }^{111}$, y en el plano catastral de Coin del 1941 ${ }^{112}$. Este vial, junto con el de la Alfaguara, articulan la margen izquierda del río y delimitan, en buena medida, el espacio de hábitat de origen andalusí. Generalmente se admite por diversos historiadores locales como el lugar donde estaba la torre-alquería. Pensamos que en este sector no se encontraba la estructura defensiva medieval debido a que su ubicación está inmediatamente por debajo de la antigua zona residencial y de dicho camino, y por encima de la acequia de la fuente de la Reyna, en un lugar de la ladera rehundido, con una visibilidad limitada, y por lo tanto con escasas cualidades defensivas. En la actualidad existe en este

107 ORdóñez FríAs, “Los sistemas de irrigación en el pago de Alpujata-Monda”. Parece que esta zona, al menos a nivel de poblamiento, fue abandonada en un momento indeterminado del siglo XV debido a la presión militar castellana concentrándose la población en la alquería de la Villeta, a las afueras del actual casco urbano de Monda, donde la existencia de un importante recinto amurallado permitía una defensa eficaz.

108 AGS, Cámara de Castilla, Libro 1, 1493, f. 76. Actualmente se conserva en buen estado la torrealquería de Jubrique.

109 AMM, AACC, Vol.1, fol.197v, 1493.

110 Madoz IBÁÑEz, Diccionario geográfico-estadístico-histórico de España y sus posesiones de Ultramar, XI, p. 514.

111 Mediante la petición de "nota simple" en el Registro de la Propiedad de Coín sobre determinadas fincas de Pereila Alta, hemos constatado la existencia de tal topónimo.

112 AHPM, Catastro Histórico, Término Municipal de Coín, Polígono 17, Hoja 1, 1941. 
lugar la denominada "Casa de la Torre" cuyos restos probablemente corresponderían con un palomar ${ }^{113}$. A colación de esto vemos como Pascual Madoz (ver nota $n^{\circ} 106$ ) a mediados del siglo XIX ya menciona la existencia de dos torres en la zona, probablemente una coincidiría con la de la alquería y la otra con la del palomar.

En la parte superior del poblamiento, por encima del arroyo de Ballenato, y por debajo del camino de la Alfaguara cuando este llega a una zona que las fuentes documentales denominan "el llano de Pereila" 114 , se ha observado una acumulación de material compuesto por abundantes bloques, con un predominio de los mampuestos y en menor medida de sillarejos, ladrillos, tejas y restos de mortero de cal repartidos por parte de la ladera a modo de derrumbe. Interpretamos que son los restos de la torre-alquería, opinión que queda reforzada por el testimonio de varios agricultores de la zona los cuales conocieron parte del alzado de esta construcción a la que denominaban como torre de don Fernando o el "Castillo". Tenemos algunos documentos que nos orientan de la situación de dicha estructura, en concreto un pleito de 1564 entre linderos de Pereila que la sitúan por encima de la juntas de los caminos de la Alfaguara y de la Torre, subiendo por un arroyo, hasta llegar a unos olivares. Esta descripción coincide, grosso modo, con el área donde se han hallado los restos antes citados que relacionamos con la torre-alquería:

...yendo el acequia en la mano saltando un mojón que esta de piedras que esta hecho antiguo junto al acequia que ally alinda $[. .$.$] y de allí va a dar a la junta de caminos$ hasta la punta de un arroyo que parte el olivar de Luis Tello de Araso y el dicho camino a los olivares de Vautista Salvado y a otros del atalayura... ${ }^{115}$.

Estas edificaciones se construyen ante la necesidad de defensa de las comunidades campesinas “...que en determinados momentos estuvieron próximas a la frontera o sometidas a incursiones militares frecuentes" 116 frente a la presión militar castellana.

Otro elemento fundamental de la mayoría de los espacios residenciales es la mezquita. Dos menciones se realizan en el Pleito de este lugar de culto: "que sabe y ha visto que en dicho lugar de Pereyla en tiempo que eran moros avia mezquita y después que se tornaron cristianos vy iglesia [...] que en tiempo de moros abia en la dicha Pereyla mezquita la qual después que son cristianos la hizieron iglesia... ${ }^{117}$. A modo de hipótesis, planteamos que su ubicación podría estar en la antigua escuela rural que aún se mantiene en pie y que anteriormente fue iglesia. Dicha edificación está en la huerta de José Jiménez Enrique a pocos metros de la casa de la Torre y también por debajo de este camino.

Por último y como lugar imprescindible asociado al área residencial, está el espacio de enterramiento. Para su localización ha sido fundamental la colaboración

${ }^{113}$ A finales del siglo XV y durante buena parte del XVI fueron muy frecuentes las autorizaciones, por parte de la Corona, para la construcción de palomares con la finalidad de obtener fertilizante para uso agrícola derivados de los excrementos de las palomas. Bejarano Pérez, Los Repartimientos de Málaga IV, p. 227 y 552.

114 AHPM, P-6554, s/f, 1564.

115 Ibidem.

116 JimÉnEZ PUERTAS, “Asentamientos rurales y frontera”, p. 392-393.

117 ACM, Pleito. 
de algunos vecinos de la zona ${ }^{118}$. La necrópolis se encuentra a unos 340 metros, por debajo del área residencia en dirección sureste y en la parte inferior del camino de la Torre cuando el terreno se suaviza y disminuye su grado de pendiente. Se ha podido apreciar, sobre el terreno, abundantes fragmentos óseos, especialmente en el talud que se realizó para ampliar el camino en 1980. También se han registrado numerosas lajas que tendría como función el cubrimiento de las tumbas.

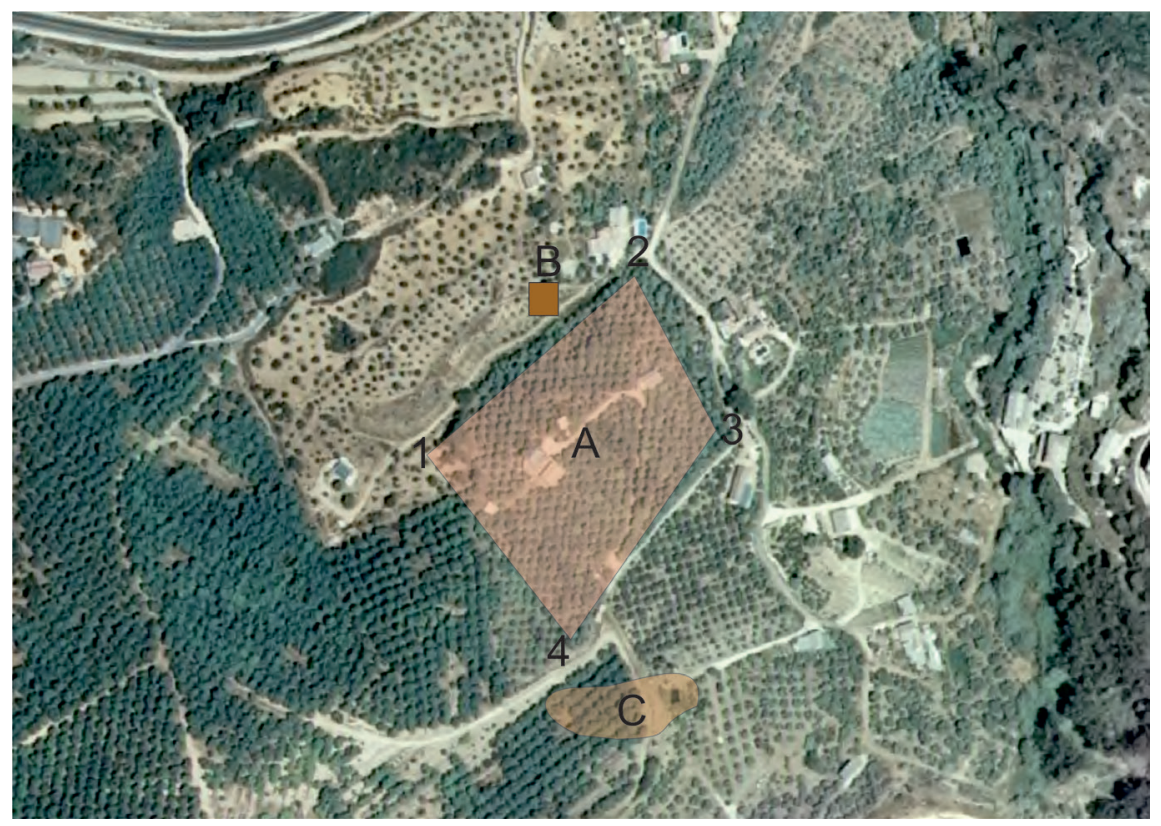

Fig. 5. Espacio residencial de la alquería de Pereila. 1. X340867.84 - Y4056292.02 - A: zona de hábitat, 2. X340748.97 - Y4056191.00 - B: Torre-Alquería, 3. X340921.68 Y4056189.18 - C: necrópolis.

Vamos a realizar un somero estudio de algunos fragmentos cerámicos, que consideramos representativos, para obtener un referente temporal sobre el yacimiento objeto de nuestro estudio. Hay que tener en cuenta que esta cerámica tiene un carácter superficial y descontextualizado al no ser fruto de una excavación de carácter científica. Sin embargo es el único registro arqueológico que nos puede proporcionar una cronológica relativa. Para su análisis se han utilizado los trabajos realizados por Melero García en los pozos de Cártama, Rambla Torralbo, Salado Escaño, Mayorga Mayorga, para la ciudad de Málaga, Ordóñez Frías en la alquería de la Villeta en Monda, Cavilla Sánchez-Molero para la cerámica almohade de Cádiz y Retuerce Velasco en su estudio de la cerámica andalusí de la Meseta ${ }^{119}$. Según la finalidad para la que fueron diseñadas los dividiremos en:

\footnotetext{
${ }^{118}$ Agradecer la colaboración de José Jiménez Enrique.

119 Melero García, "La cerámica de época nazarí del vertedero medieval de Cártama (Málaga)", pp.157171. Salado Escaño, Rambla Torralbo, y Mayorga Mayorga, "Nuevas aportaciones sobre la cerámica de época nazarí", pp. 221-257. OrdóÑEz FríAs, "La cerámica medieval y moderna de la alquería de la Villeta
} 
-Cerámica de exposición al fuego: Se ha identificado nueve bordes de cazuelas, frente a unos cuatro de marmitas, seleccionándose cuatro fragmentos que consideramos representativos; dos relacionados con el tipo cazuela y dos con el tipo marmita. Todos ellos están elaborados a torno, con pasta de tipo ferruginosa, muy depuradas y de tonalidades rojizas debido a su abundancia en componentes férricos que les proporcionan una gran resistencia al choque térmico producido por su larga exposición al fuego ${ }^{120}$. Las dos cazuelas (Fig.6, C-1 y C-2) poseen paredes convergentes y bordes invasados en forma de ala, el primero ligeramente orientado hacia arriba y el segundo de tendencia recta. Tienen recubrimientos vítreos melados en su interior y en sus bordes exteriores. Dicha tipología posee unos antecedentes almohades aunque la existencia del vidriado y el desarrollo de los borde en ala nos hace clasificarlas dentro de una cronología que oscilaría entre los siglos XIII y XIV ${ }^{121}$. De las dos marmitas, la primera (Fig.6, M-1) posee borde recto poco marcado con labio escotado de terminación redondeada y paredes convergentes, con el interior y borde exterior vidriado en melado de tendencia verdosa, tipología y recubrimiento que asociamos con el siglo XII ${ }^{122}$. La segunda (Fig.6, M-2) posee un cuello recto vertical, más desarrollado que el anterior, con borde escotado de terminación redondeada en forma de moldura saliente hacia fuera, paredes convergentes aunque con fisonomía abolsada ${ }^{123}$, estando enmarcada entre los siglos XIV y XV, ya en pleno período nazarí.

-Cerámica de presentación de alimentos: Se han identificado unos doce fragmentos de ataifores en los que diez son del tipo quebrado con vedrío en verde esmeralda en su interior, algunos con chorreones por fuera y bordes de tendencia recta con moldura triangular al exterior. Melero García los ha clasificado como de "...una cronología del tercer cuarto del siglo XIII y primero del XIV..."124. Esta tipología y recubrimiento está muy extendida en las pequeñas alquerías rurales de la comarca, poseyendo una pasta peculiar que"...presenta una composición en láminas muy característica común a todos los ataifores con recubrimiento en esmalte estannífero y en óxido de cobre dentro de la Hoya del Guadalhorce"125 (Fig.6, A-1 y A-2). Los dos restantes (Fig.6, A-3 y A-4) son también quebrados aunque con paredes más gruesas, bordes similares a los anteriores, vedrío melado en su totalidad y decoración interior con bandas en óxido de manganeso. Están confeccionados con pastas depuradas de tonalidades ligeramente rojizas. Los adscribimos a los siglos XI-XII y Cavilla Sánchez-Molero lo identifica con el periodo almohade ${ }^{126}$.

-Cerámica de usos múltiples: Se han reconocido cinco fragmentos de alcadafes todos ellos pertenecientes a bordes. Poseen un cuerpo de forma troncocónica invertida con bordes exvasados, redondeados y moldura al interior. Dos de ellos (Figs.6, AL-1 y AL-2) presentan un recubrimiento en verde esmeralda en su interior y con una crono-

(Monda-Málaga-)”, pp. 207-239. Cavilla Sánchez-Molero, La cerámica almohade de la isla de Cádiz. Retuerce Velasco, La cerámica andalusi de la Meseta.

120 Fernández Navarro, Tradición tecnológica de la cerámica de cocin, pp. 171-172.

121 Ordóñez FríAs, "La cerámica medieval y moderna”, 21, p.p. 216-217, Lám. 1. A-B. Melero GARCÍA, “La cerámica de época nazarí”, P. 164, Lám. 4-35.

122 Cavilla asocia esta tipología con un probable origen emiral extendiéndose por buena parte de al-Andalus con los imperios norteafricanos cuando ya comienza a impermeabilización con vedrío melado. Cavilla, La cerámica almohade, p.135.

${ }^{123}$ Melero García, "La cerámica de época nazarí”, 9, P. 165, Lám. 4-37.

124 Ibidem, p. 164.

125 Ordóñez FríAs, El poblamiento rural andalusí poscalifal".

126 Cavilla, La cerámica almohade, pp.159-160, Fig. $1^{\text {a }}$. 
logía que relacionamos con los siglos XIV y XV. Estos recubrimientos están bien registrados en los pozos de Cártama ${ }^{127}$ y en la alquería de la Villeta ${ }^{128}$, esta última apenas a cuatro kilómetros de distancia de Pereila.

Como hemos visto en este breve estudio de material cerámico las cronologías más antiguas corresponden con los siglos XI-XII, mientras que los fragmentos predominantes son ya nazaríes, relacionándose con los siglos XIV y XV. Es evidente que estas dataciones están realizadas sobre un material escaso y descontextualizado, que no aporta una garantía de fiabilidad, seguridad que solamente podría conseguirse mediante una excavación realizada con metodología arqueológica.

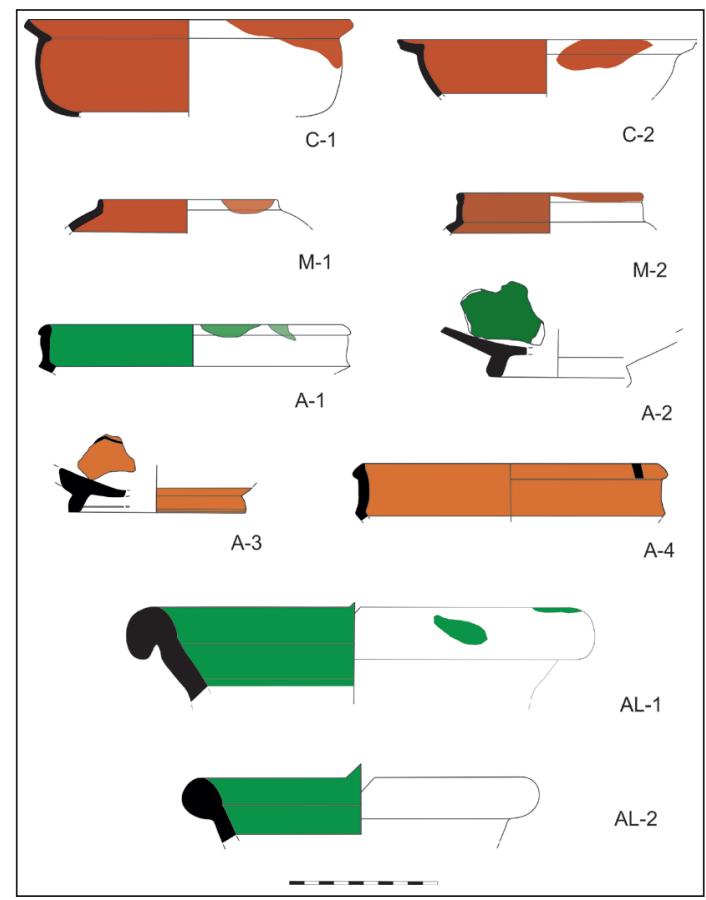

Fig. 6. Cerámica andalusí comprendida entre los siglos XI y XV.

\subsection{VALDEPERALES Y SUS ESPACIOS DE TRABAJO}

El pago de Valdeperales (Fig.7) constituía un espacio de trabajo bien definido e individualizado del núcleo principal de Pereila Alta del cual estaba separado por los partidos rurales de Viñas Viejas y el Piejo. Forma un valle, el cual se aterrazó en sentido descendente, que va desde el borde norte de la meseta de los Llanos, hasta el río de la Villa con un desnivel entre ambos puntos de 220 metros. Está delimitado por el dicho río de la Villa por el norte y oeste, por el sur por la meseta de los Llanos y por el este con el farallón del cerro Carranque o de las Lombardas, poseyendo una superficie

127 Melero García, “La cerámica de época nazarí”, 9, p. 168, Fig. 6-61.

128 Ordóñez FríAs, "La cerámica medieval y moderna”, 21, p. 230, Lám. 8. B-C. 
aproximada de $30 \mathrm{Ha}$. A nivel interno está estructurado por tres vías transversales; camino Alto, camino de En medio y camino Bajo. A su vez del camino Alto derivan cuatro viales paralelos a este y que van por los trazados de las acequias. Cada uno de estos ramales transversales marcó diversos períodos de expansión de los cultivos, con un orden de antigüedad que va de arriba a abajo. Quizá el más interesante, por ser la primera zona en la que, probablemente, se instaurara una agricultura de irrigación, sea el correspondiente al camino Alto. Este primer sector tendría como límites la meseta de los Llanos, por arriba, y el camino Alto por abajo, que correspondería, en buena parte, con las tierras de riego de la acequia del Olivar.

Valdeperales es el territorio de la antigua alquería que mejor conocemos debido a la abundante información que nos ha proporcionado el Pleito. Ello es así porque el Cabildo estaba interesado en dejar claro que la zona había pertenecido a Pereila y que los cristianos viejos, a los cuales Pedro de Barrionuevo arrendo estas tierras, tenían la obligación de pagar el diezmo a la Catedral. También se insiste pertinazmente sobre los cambios de cultivos que se produjeron desde finales del siglo XV y principios del XVI, cuando aún estas tierras estaban trabajadas por mudéjares, hasta la primera década del XVI en que todos los agricultores de Valdeperales eran ya cristianos viejos. Creemos que posee la misma intencionalidad, es decir mostrar que a pesar de los cambios de cultivos y de los cultivadores, esta zona había sido una unidad territorial con Pereila Alta. Si bien el Pleito es el que nos aporta la información mayoritaria sobre Valdeperales, no es la única fuente documental en hacerlo, y son también los Protocolos Notariales, especialmente los que van desde el intervalo temporal de 1540 a $1565^{129}$, los que complementan dicha información.

¿Pero qué tipo de agricultura se practicaba?, ¿de secano, de regadío, o ambas indistintamente? Podemos afirmar que la agricultura de irrigación era predominante como así se muestra en el Pleito: “...pero que sabe y ha visto que de tres años a esta parte Merca Nuñez del dicho Barrionuevo ha dado a tributo todas las tierra de riego de Valdeperales a vecynos de Coyn..."130. Sabemos que el número de arrendatarios era, al menos, de trece ${ }^{131}$, si todos ellos trabajaban tierras de regadío, como se alude en el texto anterior, los cultivos de irrigación debieron de ser predominantes.

La información más temprana que poseemos sobre la utilización del agua en este pago con fines agrícolas procede del denominado "Privilegio de Valdeperales" que se recogió en las ordenanzas de la ciudad de Málaga y quedo constancia documental cuando lo redactó el escribano público Rodrigo Alcázar en 1529. Dicho documento otorga una cantidad de agua fija preferente a dicho pago sobre el resto de las acequias que tienen su toma en el río Nacimiento ${ }^{132}$. Las alusiones a la existencia de acequias son frecuentes en la documentación del siglo XVI: “ $\ldots$ y de ally a dar a la acequia

129 AHPM, P-6548, P-6554 y P-6553.

130 ACM, Pleito.

131 “...Rodriguez ortelano, Alonso Fernández tundidor, Cristobal Sanchez, Pedro, Francisco Rodriguez mesonero, Fernandez de Avila sastre, Juan de Astorga, Alonso Doynoro, Juan Romero, Juan Garcia de Pulla. Bartolome Sanchez frayle, Francisco Rodryguez harriero, Alonso Marques el moço, y otros vezynos de Coyn que se la ha dado a senso Mençar Nuñez mujer de Fernado de Barrionuevo..." ACM, Pleito.

132 Dicho privilegio se otorgo debido a que con anterioridad a 1529 se produjo una inundación catastrófica en Coín debido a una crecida en el río Nacimiento. Para evitar futuras inundaciones se habilito un desvió de aguas por la acequia-arroyo de Valdeperales. 
del agua y de ally al cerro de las Lombardas... ${ }^{133}$ “...viñas y tierras calma de Anton Zyeza e la acequia por medio..." 134 . En la actualidad existen dos acequias que riegan la mayoría de las tierras de este pago; la de Valdeperales y la del Olivar ${ }^{135}$. Ambas derivan de la torna de los Negros, partidor que divide las aguas del río Nacimiento entre dichas acequias y la de la Haza. La primera discurre por el cauce de un antiguo arroyo y tiene diversas salidas a las terrazas colindantes, destacando un brazal secundario de unos 150 metros de longitud que cubre buena parte de la margen derecha de dicho arroyo. Una vez que el cauce sobrepasa el camino de En medio, pierde su función de acequia convirtiéndose, exclusivamente, en un desagüe del sistema debido a que el grado de pendiente del terreno desciende de manera notable y ya el canal es incapaz de proporcionar agua a los bancales colindantes por efecto de la gravedad. Se trata de una acequia-arroyo que tomo protagonismo como canal de riego a raíz del "Privilegio de Valdeperales" probablemente ya en la tercera o cuarta década del siglo XVI y que cubre en la actualidad una superficie de $2,9 \mathrm{Ha}^{136}$.

La acequia del Olivar riega todo el franco oriental del pago con una longitud de unos 800 metros y actualmente cubre una superficie de riego de aproximadamente 3,9 $\mathrm{Ha}^{137}$. Desde su derivación de la torna de los Negros y hasta el camino Alto, forma un tupido entramado de brazales secundarios que a su vez se dividen en subrasales y ramales que van regando las diversas huertas. Este sistema, posee una forma arborescente muy marcada con un abancalamiento irregular y compartimentado debido a una orografía compleja derivada de la existencia de una serie de pequeños paleocauces sobre los que se han diseñado las terrazas. A tenor de su morfología hay suficientes indicios para pensar que este fue el primer sector que se transformó en regadío, y por lo tanto constituyo el núcleo matriz a partir del cual se generaron las diversas ampliaciones del sistema, tanto en el período medieval, como en el moderno y contemporáneo. Si observamos la Fig. 7 vemos que con el indicativo O-1 se señala el sector original de filiación andalusí, con una superficie regada de 2,4 Ha. La primera ampliación (O-2) cubre la margen izquierda de un paleocauce de vertientes pronunciadas cuyas aguas descargaban en el río de la Villa y por cuyo centro discurre parte del camino de En medio. Forma una serie de estrechas terrazas escalonadas que se van ensanchando a medida que se aproximan al cauce del río cubriendo una superficie de riego de $1 \mathrm{Ha}$. Dada su morfología podemos englobarla dentro del parcelario andalusí, aunque en su parte inferior, colindante con el río de la Villa, ya hay muestras de una ordenación diferente lo que podría ser síntoma de una ampliación posterior. La segunda ampliación (O-3) se desarrolló por la margen izquierda del citado paleocauce, con una orientación noreste y paralelo al camino de En medio, aprovechando un marcado desnivel del terreno generando bancales de reducidas dimensiones. Ocupa

133 Ibidem.

134 AHPM, P-6554, s/f, 1564

${ }^{135}$ Las acequias del Arrumbadero y de la Haza riegan también tierras de Valdeperales. Debido a que tienen un carácter periférico con respecto al pago y sus trazados pudieron tener un probable origen moderno, no van a ser objeto de estudio en este artículo.

136 Información proporcionada por la Comunidad de Regantes Llanos a Juntillas del Nacimiento de Coín.

137 Ibidem. 
una superficie 0,5 Ha. Al igual que en la anterior también se aprecia en su parte inferior una estructuración diferente de la acequia y del parcelario.

Hay que hacer una distinción entre las huertas del sector de Pereila Alta y las tierras de riego de Valdeperales. La diferencia estriba en que los bancales cercanos al área residencial eran cultivos hortofrutícolas ${ }^{138}$ en tierras profundas y de buena calidad frente a los de Valdeperales, con especies más propias del secano que al proporcionarles algunos riegos se garantizaban las cosechas en años de escasez hídrica, además de aumentar su rendimiento. También este tipo de tierras, generalmente, estaban alejadas del núcleo residencial principal, además de ser terrenos de peor calidad ${ }^{139}$. Las fuentes escritas son muy elocuentes al afirmar que:

...se ha dado a tributo las tierras de riego de Valdeperales a vezynos de Coyn para poner viñas y majuelos y que antes que se pusiesen los dichos majuelos este testigo veya que todas aquellas tierras las solia arendar para senbrar pan y ava... [...] no estaban majuelos ni viñas en las tierras de Valdeperales salvo algunos majuelos los que se ponyan entonces llevaban havas y algunos de los tableros donde se podía sembrar trigo y cevada... ${ }^{140}$.

Algunos investigadores como López García las denominan como “...tierra de riego de campiña [...] que, aunque irrigadas, eran de menos calidad y se dedicaban al cultivo de cereales como la cebada o plantas forrajeras..." ${ }^{141}$. Igual ocurre en el pago de Mezquitilla que se integra en el término municipal de Coín a finales del XV, pero que mantiene una ocupación mudéjar y después morisca teniendo, por lo tanto, continuidad como espacio de trabajo desde época andalusí. Son frecuentes las alusiones a dicha vega durante la primera mitad del XVI, así como también se recoge en el Apeo de Guaro de 1568:

...Cupole la primera suerte subsesibe de las tierras de la media suerte de Diego García Dentudo en la vega de arriba que hera de Pedro e Juan Algolfo, vezinos de Guaro, que es en el pago de la Mezquitillas, cortando desde el río Grande hasta la acequia del riego e suertes de las tierras de secano de los pobladores de la dicha villa, linda por la cavezada baxa con el dicho Río Grande, e por la alta con la dicha acequia... ${ }^{142}$.

${ }^{138}$ En el Repartimiento de Coín se diferencia a los regadíos que se clasifican como huertas, de aquellos que no lo son: “...que no son tales (huertas) porque no tienen arboledas; el qual es syn arboledas y no es tal salvo porques de ryego" LóPEZ DE CoCA CASTAÑer, La tierra de Málaga a fines del siglo XV, p. 288, fol. 118V. Pereila Alta, sin embargo, tenía: “...algunos naranjos e morales e azeytunos e otro arboles frutales...”AGS, RGS, IV, fol. 50, 1490.

${ }^{139}$ Las tierras de Valdeperales están formadas por un sustrato base de origen calizo que ha generado suelos muy porosos que permiten un drenaje y aireación elevados, aunque con bajos porcentajes de materia orgánica y arcillas. Algunas especies arbóreas tienen dificultades para desarrollarse en esta zona, tales como naranjos, ciruelos o manzanos, sin embargo el cereal, el nogal y determinadas leguminosas si producen buenos resultados en estos terrenos (Fuentes del autor).

${ }^{140}$ ACM, Pleito.

141 López García, "Regadíos de origen andalusí en la Sierra de las Nieves: El caso de Tolox", p. 205.

142 Archivo Histórico Provincial de Granada, Libro de Poblaciones, Apeo de Guaro, Libro 6716, fol. 153$\mathrm{V}, 1571$. 
También podemos apreciar cómo se produjo un cambio de cultivos desde finales del siglo XV hasta las primeras décadas del siglo XVI, cuando estas tierras se arriendan a cristianos viejos: “....este mismo testigo que sabe que los majuelos de los vecinos (cristianos viejos) que nombra de Valdeperales el los conoció como tierra de pan que lo tenia y sembraron los morisco de Pereyla y lo encerraban en Pereyla"143. Vemos como de la siembra de cereales, alcaceres, garbanzos, entre otros, se pasa, fundamentalmente, a plantaciones de viñas y olivos. Es el reflejo de dos sociedades y dos sistemas económicos diferentes en que se evoluciona desde unos cultivos orientados a la subsistencia y al autoconsumo, a otros como la vid con una clara vocación especulativa ${ }^{144}$.

Al igual que en el sistema de la fuente de la Reyna, en Valdeperales también se observa una clara diferenciación entre las zonas de irrigación de probable origen andalusí, y aquellas fruto de ampliaciones modernas o contemporáneas. Los sectores 0-1, 0-2 y 0-3 (Fig. 7) tienen perímetros periformes con estructuras internas de canalizaciones ramificadas y formas arborescentes, que puede ser indicador de un probable origen andalusí. Si lo comparamos con el último tramo de la acequia del Olivar el contraste es evidente con brazales secundarios perpendiculares a la acequia madre generados por ampliaciones ya de época moderna. Igual ocurre con los sectores de la acequia de Valdeperales con un perímetro de forma rectangular y brazales secundarios también perpendiculares a la acequia madre (Fig. 7).

La existencia de dos sistemas de irrigaciones independientes cuyas fuentes de suministro hídrico son diferentes, y ante la presencia de un solo espacio residencial generan contradicciones con los principios de la arqueología hidráulica en que, según estos, cada acequia tiene su alquería ${ }^{145}$ y no varias acequias para uno solo de estas unidades territoriales. Aparentemente en Valdeperales las prospecciones superficiales han dado resultados negativos y no hemos hallado indicios de un posible espacio residencial. Hay que tener en cuenta que la zona está profundamente antropisada y que muchas de las parcelas han sido valladas no pudiéndose obtener autorización de la mayoría de los propietarios para prospectarlas, por lo que en este momento de la investigación no podemos emitir una hipótesis plausible para esta cuestión.

143 ACM, Protocolo. De este fragmento se deduce como había dos zonas bien diferenciadas; Pereila Alta, en cuyo poblamiento guardaban los moriscos las cosecha, y Valdeperales como sector productivo relevante, pero separado del espacio residencial.

144 Sabemos que durante los siglos XIV y XV en el emirato nazarí el cultivo de la vid y la morera eran habituales con la intención de obtener pasas y seda. Se trataba de cultivos eminentemente especulativos en que la mayoría de su producción tenían como finalidad su venta en mercados exteriores. Tras la conquista del reino de Granada los castellanos aumentan la superficie de cultivo, tanto en el secano como en el regadío, produciéndose un incremento apreciable en los plantíos de vides y morales. BEJARANo PÉREZ, Los Repartimientos de Málaga, IV, pp. 651, 652, 654, 655...

145 “...todo espacio hidráulico andalusí está siempre irrigado por un mismo brazo y nunca recibe agua de otra acequia, puesto que cada uno tenía la función de abastecer a un grupo campesino concreto y no podía mezclar el agua adjudicada a cada uno de ellos". EsQuilache MARTí, (2011): "Prospectar huertas y vegas fluviales". 


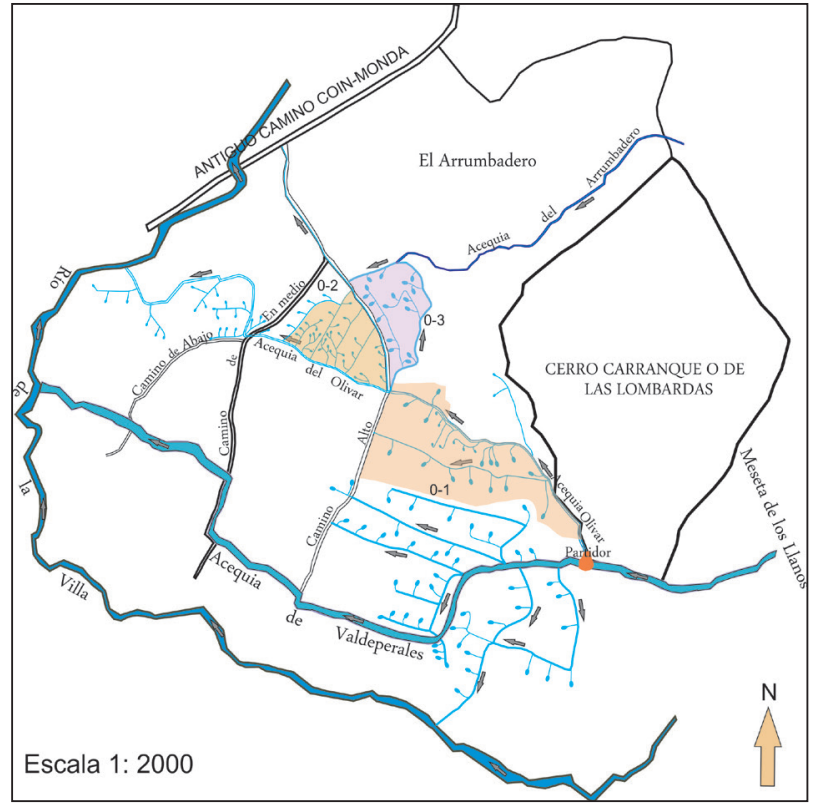

Fig.7. Los espacios de irrigación en Valdeperales. La acequias del Olivar y de Valdeperales.

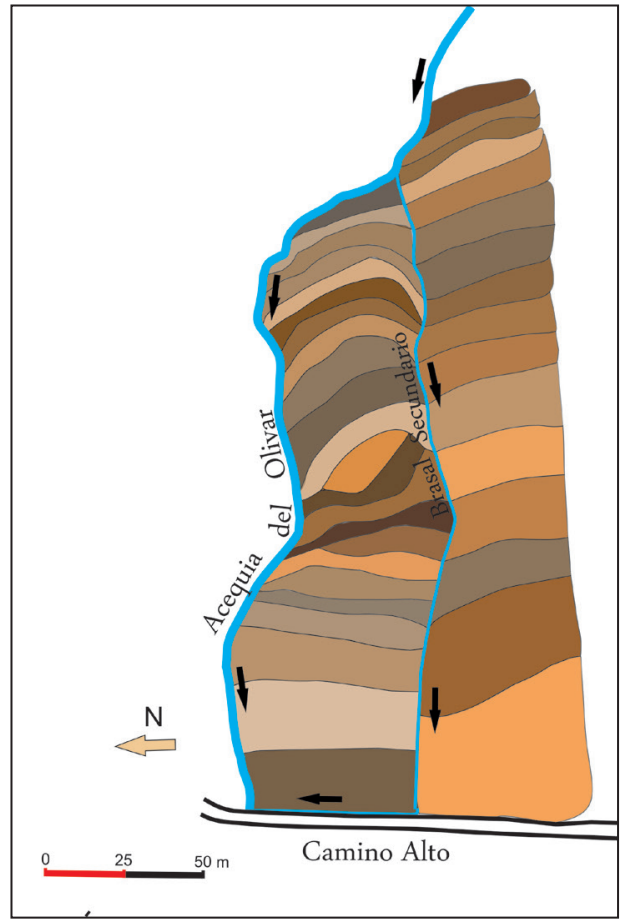

Fig. 8. El aterrazamiento y su estructura en el sector original de la acequia del Olivar. 


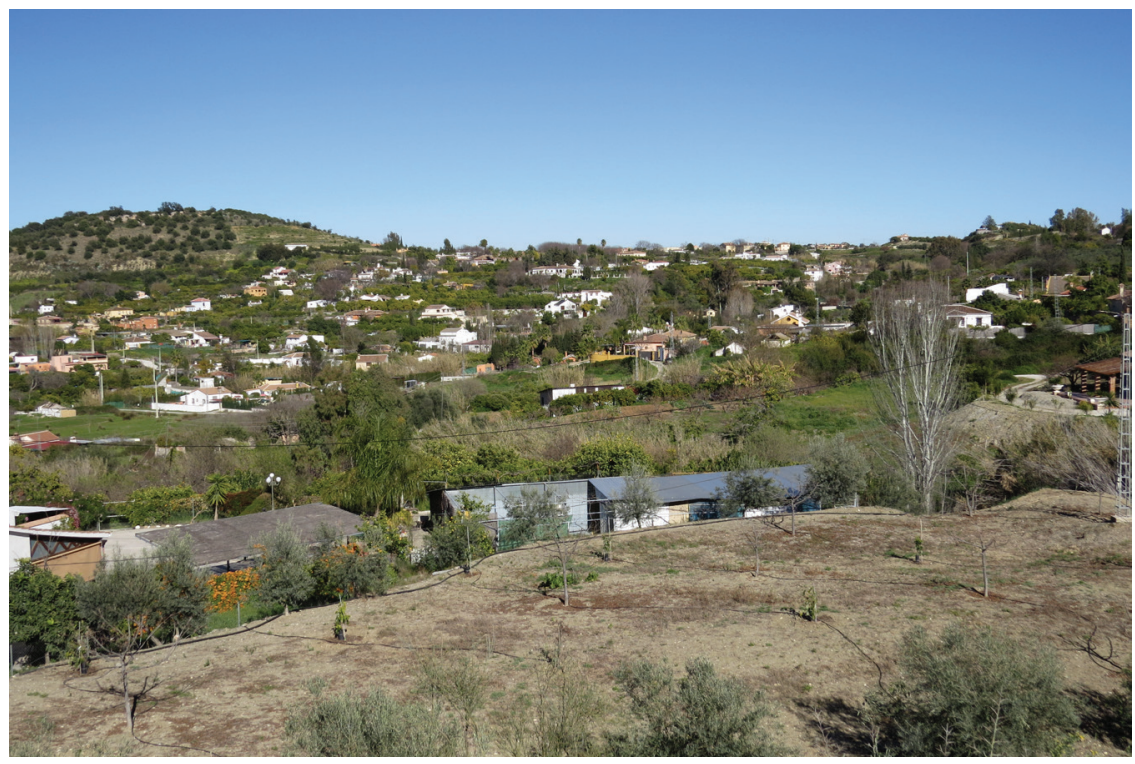

Fig. 9. Terrazas de Valdeperales.

\subsection{EL TERRITORIO COMÚN}

La existencia de territorios comunes en que podían realizar actividades económicas varias alquerías, era habitual en el período nazarí y marcaban los límites espaciales entre los diversos entes poblacionales ${ }^{146}$. En el Pleito también se especifica cuál era ese espacio común entre las alquerías de Pereila y Coín: "En tiempo de moros había el común entre Pereyla y Coyn en el cerro de las Lonbardas frente al camino de las huertas de Coyn..."147. Ubicamos esta zona en el cerro Carranque o de las Lombardas, en su vertiente sur que va descendiendo suavemente hasta conectar con el camino de los Llanos, el cual marca la divisoria entre dicho promontorio y las "...huertas de Coyn..."148, camino que también viene recogido en el Pleito como límite entre los territorios de ambas alquerías por lo que deducimos que estaba incluida esta vertiente del cerro dentro del territorio de Pereila, teniendo también Coín derecho a su utilización. Parece que su uso fue principalmente ganadero. Sin embargo las comunidades de pastos, que se habían mantenido desde época islámica, se suprime por los castellanos en $1501^{149} \mathrm{y}$ desde entonces los moriscos de Pereila Alta no pueden pastar en la cara sur del cerro Carranque ya que el concejo de Coin se lo había apropiado: “...y este testigo y otros moços andaban por ally (cerro Carranque) guardando las cabras

146 "De esta forma, el harīn o terreno comunal, podía marcar el límite del territorio en el núcleo rural" Trillo SAN José, El agua en al-Andalus, p. 55.

${ }^{147}$ ACM, Pleito.

148 Ibidem.

149 AGS, Cámara-Pueblos, leg. 11, fols. 49 y 50, 1501. 
de los de Pereyla y no osaron entrar en el término de Coyn con las cabras porque los guardas de Coyn los presaban"150.

Tenemos, por lo tanto, constancia de la existencia de una zona común entre Coín y Pereila en época nazarí. Probablemente no sería la única ya que Pereila tenía límites con al menos tres alquerías más; la Villeta (Monda), Guaro y Benamaquis, con las que posiblemente también compartiría zonas comunes.

\section{SU EVOLUCIÓN, DESDE ALQUERÍA ANDALUSí A POBLAMIENTO MUDEJAR-MORISCO}

Vamos a analizar la evolución que sufrió el territorio de Pereila desde su último período como alquería andalusí, hasta 1568 en que se expulsa la población morisca de la comarca. Para ello nos basaremos en la documentación escrita destacando las aportaciones del Pleito que proporciona información de las últimas décadas del siglo XV, cuando el lugar aún era nazarí, hasta la tercera década del XVI. De 1534 hasta 1568 la información proviene de los protocolos notariales en los que se incluyen algunos textos de interés como el del pleito por unas lindes de olivares en Pereila Alta. Finalmente también es relevante un documento tardío de 1584 en que la Corona demanda a Bartolomé Amaya por la usurpación de tierras reales especificándose parte de los antiguos límites de la alquería de Pereila.

Tras la conquista del territorio por parte de los Reyes Católicos las tierras asociadas a Coín se reparten definitivamente en 1492. Pereila, sin embargo, no figura en dicho Repartimiento ya que se otorga, mediante mercedes reales, la mitad a Pedro de Barrionuevo y la otra mitad a Rodrigo de Alcázar, el cual vende su parte a Barrionuevo:

...después que los Reyes Católicos hicieron merced a Pedro de Barrionuevo del dicho lugar (Pereila) le fue dado y señalado por el repartidor de dicho lugar y luego el bachiller Serrano corregidas y reformadas se lo confirmo [...] a Barrionuevo el viejo se le dio la mitad de Pereyla como merced y la otra a Rodrigo de Alcaçar que tenia un hojo menos y el dicho Barrionuevo merco su parte al dicho Rodrigo Alcaçar y luego lo arrendo todo a Mohama de Monda padre de este testigo ${ }^{151}$.

Sabemos que cuando Coin capitula en 1485, Pereila estaba ya despoblada: “...que al tiempo que se gano Coin estaba despoblada Pereila..."152 y que el motivo de su abandono estuvo relacionado con la fuerte presión militar castellana que se produjo durante el siglo XV. En concreto conocemos que fue una cabalgada dirigida por un tal Pernía quien realizó una incursión nocturna abandonando la población el espacio residencial y refugiándose en Coín.

Los Barrionuevo escinden las tierras de Pereila en dos lotes; el primero o Pereila Alta se arriendan a mudéjares y posteriormente a moriscos, mientras que Valdeperales, especialmente las zonas de regadío de vega, a cristianos viejos. Se intenta

\footnotetext{
${ }^{150}$ ACM, Pleito

151 Ibidem.

152 Ibidem.
} 
mantener una continuidad poblacional y productiva sobre Pereila Alta, zona donde se situaba el núcleo principal de la huerta de origen andalusí. Para ello era necesario mantener las estructura y la tradición productiva anterior. Como hemos visto, no hubo una continuidad poblacional ya que los habitantes musulmanes abandonan el espacio residencial antes de la caída de Coín. Ese aspecto se pretendió suplir repoblándola con colonos mudéjares y moriscos de las zonas colindantes:

...Juan Guzman sastre vecino de Coyn declara tener noticias del lugar de Pereyla desde el año quinientos siete a esta parte porque de niño fue a ese lugar de Pereyla retraido el y su padre y huyendo de la pestilencia de Coyn donde este vezyno era se refugio con su padre en Pereyla y vio como estaba poblada de moriscos nuevos de moros y no vivía entre ellos ningún cristiano viejo [...] tienpo después se despobló y se volvió a poblar, lo poblo Fernan Diañez de Barrionuevo [...] que de tres años a esta parte Nuñez de Barrionuevo ha dado a tributo todas las tierras de riego de Valdeperales a vezynos de Coyn para poner viñas y majuelos en ellas [...] que de aber syete años poco mas o menos que este testigo y otros moriscos vecinos de Hoxen que se llama Juan Alrulquy y otro Almoaz vecino de Guaro y otro que se llama Alonso Harban vezino de Hoxen tomaron arrendado las tierras y huertas del termino de Pereyla ${ }^{153}$.

Durante toda la primera mitad del siglo XVI Pereila se mantuvo como un poblamiento morisco semiautónomo con la presencia ocasional de los Barrionuevo y de los beneficiados de Coín que periódicamente impartían misa y realizaban bautismos en su pequeña iglesia ${ }^{154}$. Ya a mediados del siglo XVI existe un nuevo propietario de Pereila Alta; Bartolomé de Amaya junto con una serie de pequeños arrendatarios moriscos y propietarios vecinos de Coín. Se sigue apreciando una clara dicotomía entre cultivos de secano-cristianos viejos y cultivos de regadío-cristianos nuevos, evidencia de que se prefería la población de tradición andalusí para los dichos cultivos de irrigación:

...Bernardino Albayre vecino del lugar de Pereyla juridicion de la dicha ciudad e dixeron que por quanto el e otros varones conpañeros tomaron a renta e vecindad del señor Bartolome Amaya vecino de la dicha billa (Coín) la dicha alcaria e lugar de Pereyla con ciertos pagos e huertas y tierras e morales... ${ }^{155}[\ldots] \ldots$...los presentes Francisco Sanchez Pinto vecino desta dicha villa que entre ellos han tratado y tratan de las lindes y mojones questan y dividen entre dos olivares que los susos dichos tienen y poseen en termino desta villa (Coín) en los llanos que dicen de Pereyla... ${ }^{156}$.

Llama la atención como es una constante en las fuentes escritas que se siga denominando alquería a Pereila Alta durante todo el siglo XVI, único caso de poblamiento al que se clasifica con esta nomenclatura en la zona occidental del antiguo obispado de Málaga. El caso más cercano sería el lugar de Guaro habitado hasta 1568 casi ex-

\footnotetext{
${ }^{153}$ Ibidem.

${ }^{154}$ Se alude con frecuencia a Gonzalo de Triguero, uno de los beneficiados de Coín, el cual acudía periódicamente para impartir misa. ACM, Pleito.

${ }^{155}$ AHPM, P-6548, s/f, 1553

156 AHPM, P-5454, s/f, 1564.
} 
clusivamente por moriscos “... en la dicha villa de Guaro todos heran moriscos ezepto tres o quatro cristianos biejos que havia..."157, pero en ningún momento se clasifica como alquería. Todavía en 1582 cuando la presencia del pueblo morisco comenzaba a ser un recuerdo en la comarca, aun se le sigue denominando con este término: “...a vista del camino de Monda como viene del dicho lugar a la dicha alquería de Pereyla..." 158 .

\section{CONCLUSIONES}

En este trabajo hemos estudiado la alquería bajomedieval de Pereila y su evolución tras la conquista castellana del territorio. El final del período nazarí queda parcialmente reflejado en el Pleito, en concreto en el aspecto territorial con una serie de hitos topográficos que nos permiten delimitar su antiguo territorio, y en menor medida la faceta productiva, apreciándose claras reminiscencias de una economía basada en una agricultura de irrigación. En esta etapa la cercana Dakwan era el centro rector de la comarca, en una segunda mitad del siglo XV convulsa, donde la creciente presión militar castellana produjo una reestructuración poblacional que supuso la desaparición de los pequeños núcleos rurales y la concentración de su población en aquellas "medinas" muradas donde sus estructuras defensivas y los recursos humanos permitían una defensa eficaz frente a las incursiones castellanas. Reflejo de ello es la posesión de una torre-alquería, y de cómo en un momento indeterminado del siglo XV una cabalgada castellana ataca el espacio residencial huyendo su población y refugiándose de forma permanente en Dakwan. Similares hechos también se generaron en otras zonas del emirato nazarí, especialmente en aquellos poblamientos más cercanas a la frontera.

Tras la conquista castellana se producen profundas transformaciones tanto a nivel territorial como poblacional. Las antiguas circunscripciones que constituían las alquerías, en la mayoría de los casos, se modifican totalmente, siendo absorbidas por villas de mayor entidad. Así el territorio de Pereila se divide en dos pagos rurales diferenciados; Pereila Alta y Valdeperales, ambos se integran dentro del término municipal de Coín. A nivel poblacional, aquellas zonas donde los residentes de origen musulmán fueron expulsados, dichas transformaciones tuvieron un mayor calado y el territorio fue ocupado por colonos cristianos estableciéndose una sociedad similar a la del valle del Guadalquivir. Tales son los casos de las principales villas y ciudades de la comarca como ocurrió con Dakwan/Coín, Cártama, Álora, Marbella y Málaga, y que dieron lugar a los Repartimientos de finales del siglo XV. Sin embargo aquellos núcleos que pactaron su rendición con los castellanos tuvieron una continuidad poblacional mudéjar-morisca, en una comarca (la antigua Algarbía malagueña) en que la población de origen andalusí quedo relativamente aislada del núcleo morisco de la Serranía de Ronda y de la Axarquía, formando un territorio continuo compuesto por las villas de Ojén, Istán, Monda, Guaro, Tolox, Yunquera y Casarabonela, aunque todas ellas, en mayor o menor medida, recibieron también repobladores castellanos.

157 AHPG, Libro de Población, Libro 6716, Libro de Apeo de Guaro, Fol. 058-V, 1571.

158 AMM, Vol. 123, Libro de Composiciones de Tierras, fol. 153, 1582. 
No fue así en el caso de Pereila con una población mudéjar-morisca que permaneció durante toda la primera mitad del siglo XVI, sin que se produjeran asentamientos de residentes cristianos viejos. Si comparamos esta situación con la de la actual provincial de Granada para el mismo período, vemos como ocurría algo similar en las principales villas cuyos cascos urbanos y alfoces pasaron íntegramente a manos castellanas. Igual sucede en las zonas rurales en que existieron diversos sectores moriscos separados entre ellos.

También se observa como a mediados del siglo XVI los cristianos viejos van ocupando, progresivamente, tierras que tradicionalmente trabajaba la población morisca. En el caso de Pereila Alta, y para el mismo período, se producen arrendamientos de terrenos en la zona de riego de la fuente de la Reyna, rompiendo la trayectoria de ocupación morisca en este pago. También se constata dicha tendencia en el pago de Mezquitilla y en las villas de Monda y Guaro, donde los cristianos viejos van paulatinamente adquiriendo propiedades, o bien tomándolas como arrendatarios, como así parece mostrarse en los protocolos notariales del siglo XVI. ¿Aumento demográfico de la población de cristianos viejos, usurpación de las mejores tierras en manos de moriscos? Por ahora no tenemos suficientes datos para formular una hipótesis plausible.

Como conclusión podemos afirmar que Pereila fue una alquería de origen islámico que tuvo una evolución atípica, única dentro de la antigua Algarbía malagueña, ya que mantuvo, exclusivamente, una población mudéjar-morisca desde finales del siglo XV y durante toda la primera mitad del siglo XVI. Es un reflejo de la herencia andalusí que se manifiesta de forma más marcada que en el resto de los núcleos poblacionales de mayoría morisca a pesar de haber sufrido amputaciones territoriales de importancia como fue la pérdida de Valdeperales.

\section{BIBLIOGRAFÍA}

Acién Almansa, Manuel y Rambla Torralbo, Antonio, "La evolución de un hisn musulmán. Actuación arqueológica en el castillo de Monda", Mainake XIII-XIV, Málaga, Diputación de Málaga, 1991-91, pp. 273-294

Acién Almansa, Manuel, Ronda y su Serranía en tiempo de los Reyes Católicos, Málaga, 1977.

Ahmad Mujtar al-Abbadi, "Muhammad V Al-Gani Bi-llah, rey de Granada. Segundo reinado de Muhammad V." Miscelánea de estudios árabes y hebraicos, Vol. XII-XIII, n 1 , 1963, p.32.

Ballesteros Arias, Kirchner, Fernández Mier, Ortega Ortega, Quirós Castillo, Retamero, Sitjes, Torró y Vigil-Escalera Guirado, "Por una arqueología agraria de las sociedades medievales hispánicas. Propuesta de un protocolo de investigación", Por una arqueología agraria. Perspectiva de investigación sobre espacios de cultivo en las sociedades medievales hispánicas, BAR International, Serie 2062, Oxford.

Barceló Árbol, Miquel, Kirchner, Helena, Argemí Relat, Mercè, Navarro, Carmen, Cressier, Patrice, "Glosario de términos hidráulicos", en El agua en la agricultura de Al-Andalus, 1995. 
BARCEló, Miquel, "El diseño de los espacios irrigados en al-Andaluz: Un enunciado de principios generales", I Coloquio de Historia y Medio Físico, Almería, Instituto de Estudios Almerienses, 1989.

Bazzana, Andrés, Cressier, Patrice y Guichard, Pierre, Les chăteaux ruraux d'al-Andalus. Histoire et archēologie des husūn de Sud-Est de l'Espagne, Madrid, 1998.

Bazzana, Andre y Meleumeester, Johnny, "Irrigations sysitems of islamic origin in the valle de Ricote (Murcia, Spain)", Ruralia II, 1998, pp. 152-160.

Bejarano Pérez, Rafael, Los Repartimientos de Málaga IV, Málaga, Ayt. Málaga, 2004.

Bejarano Robles, Francisco, Los Repartimientos de Málaga I, II, III y V, Málaga, Ayt. de Málaga, 1985, 1990, 1998 y 2000.

Bermúdez Mendez, Manuel y Martín Chicano, Pilar, Coin en 1572 según el Catastro de Ensenada, Málaga, Diputación de Málaga.

Boletín Oficial de la Junta de Andalucía, n83, 1987, pp. 4717-4720.

Cabrillana Ciezar, Nicolas, El problema de la tierra en Málaga: Pueblos desaparecidos, Málaga, Unicaja, 1993.

Cavilla Sánchez-Molero, Francisco, La cerámica almohade de la isla de Cádiz, Cádiz, Universidad de Cádiz, 2005.

Espinar Moreno, Manuel, "La población de Durcal del Valle de Lecrín en el libro de habices del año 1502", Anaquel de estudios árabes 20, Madrid, Universidad Complutense, 2009, pp.57-82.

Esquilache Martí, F., "Prospectar huertas y vegas fluviales. El estudio del paisaje histórico andalusí de las huertas de Valencia: Arqueología y análisis morfológico". www.arqueologiamedieval.com/articulos, 2011, [Fecha de revisión: 24/01/2015]

Fernández Navarro, Esteban, Tradición tecnológica de la cerámica de cocina almohadenazarí, Granada, 2008.

Galán SÁnchez, Angel, "Poder y fiscalidad en el reino de Granada tras su conquista: algunas reflexiones", Studia histórica. Historia medieval, 30, 2012, pp. 67-98.

GARCía SANJuÁn, Leonardo, Introducción al reconocimiento y análisis arqueológico del territorio, Ariel, Barcelona, 2005.

GLICK, Thomas F., "El sentido arqueológico de las instituciones hidráulicas. Regadío bereber y regadío español", Aragón vive su historia: actas de las II Jornadas Internacionales de Cultura Islámica, Teruel, 1990

Gómez Armada, Francisco y Martínez Enamorado, Virgilio, Repartimiento de los bienes de los moriscos de Casarabonela, Málaga, Ayto. de Casarabonela, 2014.

GUINOT RodRíGUEz, Enric, "El paisaje de la huerta de Valencia. Elementos de interpretación de su morfología espacial de origen medieval", Historia de la ciudad de V. Tradición y progreso, Valencia, Universidad de Valencia, 2008, pp. 98-111.

KIrChNer, Helena y Navarro, Carlos “Objetivos, métodos y práctica de Arqueología hidráulica”, Arqueología y Territorio Medieval, Jaén, Universidad de Jaén, 1, 1994, pp. 159-182.

JimÉNEZ PuerTas, Miguel, “Asentamientos rurales y frontera: Las torres de alquería de las tierras de Loja en época nazarí", Carmen Trillo (ed), Asentamientos Rurales y Territorio en el Mediterráneo Medieval, Granada, 2002, p.392-393. 
KirChNer, Helena y NAVArro, Carmen, "El diseño de espacios irrigados en al-Andalus: Un enunciado de principios generales", El agua que no duerme, Granada, El legado andalusí, 1996.

KIRCHNER, Helena, "Redes de asentamientos andalusíes en Mallorca”, Por una arqueología agraria. Perspectivas de investigación sobre espacios de cultivo en la sociedad medieval hispánica, BAR International, Serie 2062, Oxford.

LóPeZ De Coca CAStaÑer, José Ignacio, La tierra de Málaga a fines del siglo XV, Granada, Universidad de Granada, 1977.

López García, Esteban, "Regadíos de origen andalusí en la Sierra de las Nieves: El caso de Tolox", p. 205.

LóPez GARCíA, Esteban, "El regadío de origen andalusí en la Sierra de las Nieves. El caso de Tolox (1485-1572)", Takurunna n², 2012, pp.187-216.

Madoz IbáÑez, Pascual, Diccionario geográfico-estadístico-histórico de España y sus posesiones de Ultramar, Fondos antiguos de la Universidad de Granada, Tomo XI, 1846-1850.

Malpica Cuello, Antonio, "El estudio del paisaje y la práctica de la arqueología del paisaje en el antiguo reino de Granada", Análisis de los paisajes históricos. De al-Andalus a la sociedad feudal, Granada, Universidad de Granada, 2009.

Malpica Cuello, Antonio, "El territorio de Loja a finales de la Edad Media: Reflexiones sobre las transformaciones castellanas en el Reino de Granada", Arqueología y territorio medieval 10,2, Jaén, Universidad de Jaén, 2001, pp. 233-254.

Malpica Cuello, Antonio, Turillas, alquería del Alfoz sexitano, Granada, Universidad de Granada, 1984.

Marmolejo Cantos, Francisco, El castillo de Benamaquís. Límites y localización histórica, Coín, Fundación García Agüera, 2014.

Martínez EnAmorado, Virgilio, "La Algarbía como realidad geohistórica en el período de formación de Al-Andalus. Una aproximación al estudio de su poblamiento rural", Arqueología y patrimonio en la Algarbía malagueña, Martín Ruíz, Juan Antonio (Ed.) Diputación Provincial de Málaga. pp. 57-95.

Martínez EnAmorado, Virgilio, Al-Andalus desde la periferia. La formación de una sociedad musulmana en tierras malagueñas (siglos VIII-X), Málaga, Diputación Provincial de Málaga, 2003.

Martínez EnAmorado, Virgilio, Torrox. Un sistema de alquerías andalusíes en el siglo XV según su Libro de Repartimiento, Málaga, Ajbar, 2006.

Melero García, Francisco, "La cerámica de época nazarí del vertedero medieval de Cártama (Málaga), Arqueología y Territorio 9, Granada, Universidad de Granada, 2012

NAVArro, Carmen, "El tamaño de los sistemas hidráulicos de origen andalusí. La documentación escrita y la arqueología hidráulica", II Coloquio Historia y Medio Físico. Agricultura y Regadio en al-Andalus, Almería, 1996.

OrdóÑEz FríAs, Antonio "Los sistemas de irrigación en el pago de Alpujata-Monda- (Málaga)", Miscelánea Medieval Murciana, en prensa.

OrdóÑEz FríAs, Antonio "Los sistemas de irrigación en el pago de Alpujata-Monda- (Málaga).", Miscelánea Medieval Murciana, 2014, en prensa.

OrdóÑEZ FríAs, Antonio, "Hidráulica y poblamiento andalusí en el valle de Jorox. Una aproximación desde la metodología arqueológica", Takurunna 3, Ronda, Edt. La Serranía, 2015. 
OrdóÑEz FríAs, Antonio, "La cerámica medieval y moderna de la alquería de la Villeta, Monda, Málaga", Arqueología y Territorio Medieval 21, Jaén, Universidad de Jaén, 2014, pp. 207-240.

OrdóÑEz FríAs, Antonio, "Los sistemas de irrigación de origen andalusí en el pago de Alpujata-Monda- (Málaga). Una reconstrucción desde el Libro de Repartimiento y Apeo, y la metodología de la arqueología hidráulica”, Miscelánea Medieval Murciana 38, Murcia, Universidad de Murcia, 2014.

ORDóÑEz FríAS, Antonio: El poblamiento rural andalusí poscalifal en la subcuenca de río Grande. Estructura territorial y pautas de asentamiento, UNED, Trabajo Fin de Máster Inédito.

Peinado Santaella, Rafael Geraldo, “Una aportación documental sobre el poblamiento, el paisaje agrario y la propiedad de la tierra de dos alquerías de la vega de Granada: Chauchina y el Jau a finales del período nazarí", Revista del Centro de Estudios de Granada y su Reino 10-11, Granada, Universidad de Granada, 1996-1997, pp. 19-92.

Perez de Pulgar, Hernando, Crónica de los señores Reyes Católicos don Fernando y doña Isabel de Castilla y Aragón. Capítulo XLII. Alicante, Biblioteca Virtual Miguel de Cervantes. Reproducción digital de la edición original de Valencia de Benito Monfort, Madrid, 1780

Retuerce Velasco, Manuel, La cerámica andalusí de la Meseta, Volúmenes I y II, Madrid, Cran, 1978.

Salado Escaño, Juan Bautista, Rambla Torralbo, José Antonio y Mayorga Mayorga, Antonio, "Nuevas aportaciones sobre la cerámica de época nazarí en la ciudad de Málaga", Cerámica nazari y merini, Transfetana 4, Ceuta, Instituto de Estudios Ceutíes, 1999, pp. 221-257.

TriLlo SAN José, Carmen, "La alquería y su territorio en Al-Andalus: estrategias sociales de organización y conservación", Arqueología Espacial 26, Teruel, Universidad de Zaragoza, 2006, pp. 243-262.

Trillo SAn José, Carmen, El agua en al-Andalus, Granada, Ed. Sarriá, 2009.

Urbano Pérez, José Antonio, La villa de Monda en el siglo XV, Monda, 1950. 